\title{
Brief Stimulus Exposure Fully Remediates Temporal Processing Deficits Induced by Early Hearing Loss
}

\author{
DDavid B. Green, Michelle M. Mattingly, Yi Ye, Jennifer D. Gay, and $₫$ Merri J. Rosen \\ Department of Anatomy \& Neurobiology, Northeast Ohio Medical University, Rootstown, Ohio 44272
}

In childhood, partial hearing loss can produce prolonged deficits in speech perception and temporal processing. However, early therapeutic interventions targeting temporal processing may improve later speech-related outcomes. Gap detection is a measure of auditory temporal resolution that relies on the auditory cortex $(\mathrm{ACx})$, and early auditory deprivation alters intrinsic and synaptic properties in the ACx. Thus, early deprivation should induce deficits in gap detection, which should be reflected in ACx gap sensitivity. We tested whether earplugging-induced, early transient auditory deprivation in male and female Mongolian gerbils caused correlated deficits in behavioral and cortical gap detection, and whether these could be rescued by a novel therapeutic approach: brief exposure to gaps in background noise. Two weeks after earplug removal, animals that had been earplugged from hearing onset throughout auditory critical periods displayed impaired behavioral gap detection thresholds (GDTs), but this deficit was fully reversed by three $1 \mathrm{~h}$ sessions of exposure to gaps in noise. In parallel, after earplugging, cortical GDTs increased because fewer cells were sensitive to short gaps, and gap exposure normalized this pattern. Furthermore, in deprived animals, both first-spike latency and first-spike latency jitter increased, while spontaneous and evoked firing rates decreased, suggesting that deprivation causes a wider range of perceptual problems than measured here. These cortical changes all returned to control levels after gap exposure. Thus, brief stimulus exposure, perhaps in a salient context such as the unfamiliar placement into a testing apparatus, rescued impaired gap detection and may have potential as a remediation tool for general auditory processing deficits.

Key words: auditory cortex; development; gap detection; hearing loss; remediation; temporal coding

Significance Statement

Hearing loss in early childhood leads to impairments in auditory perception and language processing that can last well beyond the restoration of hearing sensitivity. Perceptual deficits can be improved by training, or by acoustic enrichment in animal models, but both approaches involve extended time and effort. Here, we used a novel remediation technique, brief periods of auditory stimulus exposure, to fully remediate cortical and perceptual deficits in gap detection induced by early transient hearing loss. This technique also improved multiple cortical response properties. Rescue by this efficient exposure regime may have potential as a therapeutic tool to remediate general auditory processing deficits in children with perceptual challenges arising from early hearing loss.

\section{Introduction}

During development, extended periods of sound exposure or deprivation can have long-lasting effects on auditory perception

\footnotetext{
Received April 4, 2017; revised June 24, 2017; accepted July 8, 2017.

Author contributions: D.B.G. and M.J.R. designed research; D.B.G., M.M.M., Y.Y., J.D.G., and M.J.R. performed research; D.B.G. and M.J.R. analyzed data; M.J.R. wrote the paper.

This work was supported by National Institutes of Health Grant R01DC013314 to M.J.R. We thank Alexander Galazyuk for the generous use of his acoustic startle equipment; Sharad Shanbhag for his custom-written neurophysiology software suite, TytoLogy; Yale Cohen and Antje Ihlefeld for contributing Matlab code for the ideal observer analysis; and A. Galazyuk, J. Wenstrup, and S. Shanbhag for helpful ideas, discussions, and/or comments on the manuscript.

The authors declare no competing financial interests.

Correspondence should be addressed to Merri J. Rosen, Department of Anatomy \& Neurobiology, Northeast Ohio Medical University, 4209 State Route 44, P.0. Box 95, Rootstown, 0H 44272. E-mail: mrosen@neomed.edu.
}

(Han et al., 2007; Zhang et al., 2008; Sun et al., 2011; Rosen et al., 2012; Buran et al., 2014; Gay et al., 2014; Zhu et al., 2014). A noteworthy problem of this nature is conductive hearing loss (CHL) accompanying otitis media, which is the most commonly diagnosed childhood illness in the United States (Lanphear et al., 1997). Early CHL induces deficits in the perception of rapidly changing sounds, including speech (Whitton and Polley, 2011). CHL through the critical period of auditory development raises thresholds for signal detection in noise, reduces comodulation masking release, and increases amplitude and frequency modulation thresholds (Rosen et al., 2012; Buran et al., 2014; Gay et al., 
2014; Ihlefeld et al., 2016). These impairments can persist long after the restoration of peripheral sensitivity (Hall and Grose, 1994; Whitton and Polley, 2011; Caras and Sanes, 2015). Even if they resolve, early perceptual challenges increase the risk for long-term language processing issues (Gravel et al., 1996; Catts et al., 1999). The detection of short gaps in sound is an essential cue for vocal communication (Eggermont, 2015), and is widely used to assess temporal resolution abilities. Here we examine how hearing loss and remediation affect this important measure of temporal sensitivity.

The effects of developmental hearing loss implicate neural changes beyond the auditory periphery. Early CHL, either longlasting or transient, alters intrinsic and synaptic properties of auditory cortical (ACx) neurons (Xu et al., 2007; Mowery et al., 2015). Perceptual deficits resulting from critical-period CHL or sound exposure are accompanied by altered ACx representations (Zhang et al., 2002; Chang and Merzenich, 2003; Han et al., 2007; Rosen et al., 2012; Köver et al., 2013). In particular, an intact ACx is required for detection of short gaps (Ison et al., 1991; Kelly et al., 1996; Syka et al., 2002; Threlkeld et al., 2008). Furthermore, the perception of gaps specifically relies on $\mathrm{ACx}$ inhibitory activity (Weible et al., 2014), and developmental hearing loss alters ACx inhibitory synaptic strength, kinetics, shortterm plasticity, and receptor localization (Sanes and Kotak, 2011). In the ACx, optogenetic manipulation of neural activity shifts behavioral GDTs (Weible et al., 2014), demonstrating a causal relationship between ACx gap responses and perceptual GDTs. This relationship explains concurrent age-related changes seen in neural and behavioral gap detection (Barsz et al., 2002; Hamann et al., 2004; Diedler et al., 2007; Harris et al., 2012; Zhao et al., 2015). We therefore predicted that developmental CHL should worsen both behavioral and cortical GDTs. We raised animals with transient CHL during the auditory critical period and demonstrated lasting effects on both behavioral and neural GDTs after full hearing restoration.

Having induced a strong temporal deficit, we measured the effectiveness of brief unattended stimulus exposure as a remediation method. In children, GDTs are predictive of future languageperception abilities (Benasich et al., 2006; Muluk et al., 2011), emphasizing a need for early intervention. Active acoustic experience has a greater capacity to improve perceptual abilities and change neural substrates than equivalent durations of passive exposure (Zhou and Merzenich, 2009; Sarro and Sanes, 2011; Vollmer and Beitel, 2011; Benasich et al., 2014). However, passive exposure is easily applied and improves perception when presented in conjunction with attended tasks (Seitz and Watanabe, 2003; Amitay et al., 2006; Wright et al., 2010), reflecting implicit perceptual learning (i.e., performance improvement). We have recently demonstrated a form of implicit learning resulting from brief sessions of passive, unattended exposure to specific sound stimuli (gaps of short durations in noise; Green et al., 2016). Here we demonstrate that both behavioral and neural deficits were fully remediated by three $1 \mathrm{~h}$ sessions of stimulus exposure. For children at risk of perceptual problems, early remediation via simple stimulus exposure could be an easily implemented therapeutic option.

\section{Materials and Methods}

\section{Subjects}

All procedures relating to the maintenance and use of animals were approved by the Institutional Animal Care and Use Committee at Northeast Ohio Medical University. Male $(n=34)$ and female $(n=51)$ Mongolian gerbils (Meriones unguiculatus) from multiple litters were housed with littermates in a $12 \mathrm{~h}$ light/dark cycle. Animals were assigned to one of four treatment groups: Control-Silence (CtSil; $N=24$ ), Earplug-Silence (EPSil; $N=28$ ), Control-Gaps (CtGap; $N=17$ ), or Earplug-Gaps (EPGap; $N=16$ ). All groups underwent behavioral gapdetection testing, and a subset of animals from each group underwent neurophysiological recordings (CtSil: $N=14 ;$ EPSil: $N=17$; CtGap: $N=$ 8; EPGap: $N=8$; 28 females; 19 males). Animals for neurophysiology were chosen from each group without regard to behavioral performance. Each animal yielded a variable number of neurons for analysis, so recordings were conducted until a sufficient number was collected across groups (see Results).

\section{Experimental design and stimulus exposure}

The experimental design is shown in Figure 1A. EPSil and EPGap animals were earplugged from postnatal day $(\mathrm{P}) 11$ through $\mathrm{P} 24$, while CtSil and CtGap animals were sham-treated. On P24, P27, and P30, EPGap and CtGap animals were placed in the testing environment for $1 \mathrm{~h}$ and exposed to the same gaps in background noise used during later behavioral testing, but without any startle stimuli. On the same $3 \mathrm{~d}$, EPSil and CtSil animals were placed for $1 \mathrm{~h}$ in the testing environment without any auditory stimuli (no startle, background noise, or gaps). On P33, P36, and P39, all animals were behaviorally tested in $1 \mathrm{~h}$ sessions. Over the next 8 d (P39-P46), animals underwent cortical recordings (one animal per day; the order was randomized across groups).

\section{Mild conductive hearing loss induced with bilateral earplugs}

Transient mild CHL was induced in EPGap and EPSil animals by inserting malleable plugs (Loctite Fun-tak, Henkel) into each ear canal beginning on P11. Pups were manually restrained and positioned underneath a stereo microscope, and the pinna was manipulated to fully visualize the ear canal. Earplugs, preformed into small cylinders sized for the age of the animal, were inserted into each ear canal with blunt forceps to form a seal, then sealed in place with a small drop of cyanoacrylate. Earplugs were checked twice daily and reinserted as necessary. Before P16, ear- 
A GDTs each session

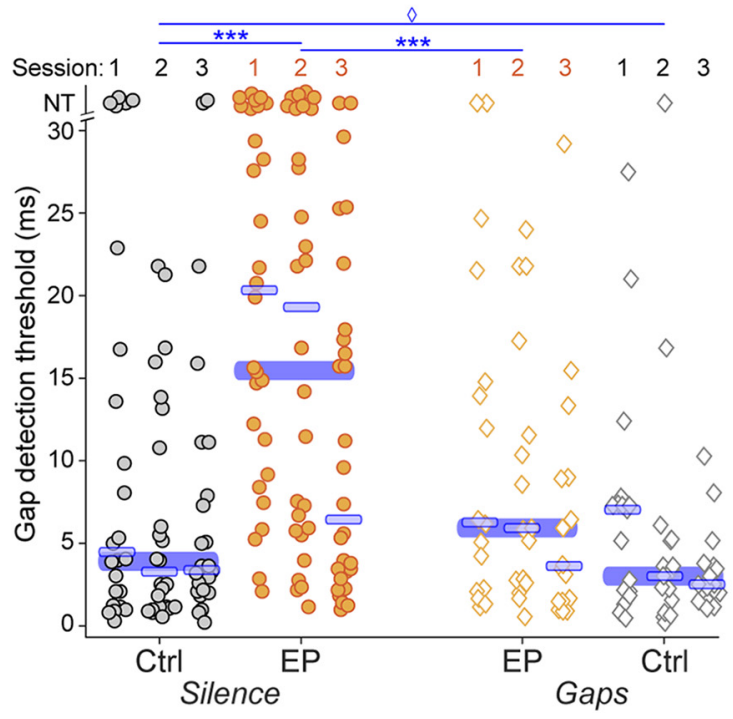

B Best across sessions

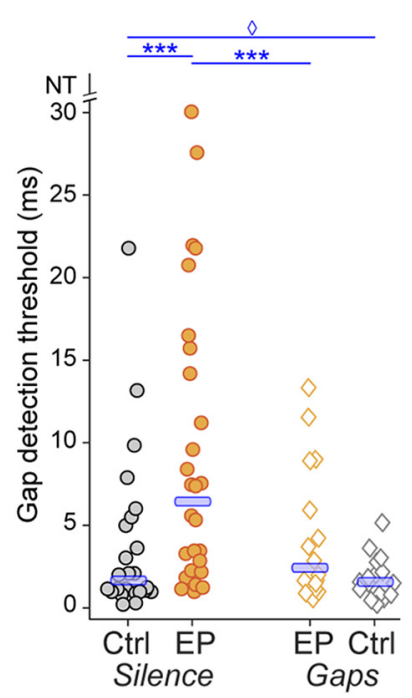

(Ison et al., 1973). Sessions lasted $1 \mathrm{~h}$. Testing was conducted once every $3 \mathrm{~d}$. This intersession interval allowed us to reduce habituation effects over sessions (Parisi and Ison, 1979), where habituation is the gradual reduction of the startle-only response magnitude (i.e., the ASR).

\section{Behavioral data analysis}

A GDT was calculated for each animal at each session using custom Matlab scripts (Mathworks, RRID:SCR_001622; D. Green and M. Rosen), as described previously (Green et al., 2016; Longenecker et al., 2016). First, the response magnitude to the startle stimulus was assessed using the root mean square (RMS; the area under the response curve) in the time window 20-50 ms after startle stimulus onset. For all trial types (startle-only or any gap duration), the distribution of RMS responses had a strong positive skew. A $\log 10$ transform was found to be the best at generating a normal distribution of RMS responses within each trial type, as assessed using the Anderson-Darling test. Then, using a bootstrap method, we determined for each trial type the RMS response threshold at which a reduction in startle was considered statistically significant. To do so, the median values of the peak-transformed responses for startle-only and each gap duration were plotted, and a cubic spline was fitted to this plot, creating a detection function. To find

Figure 2. Behavioral GDTs are worsened by early hearing loss, and remediated to control levels by stimulus exposure. $A$, GDTs for each animal over each of three sessions. $\boldsymbol{B}$, Best GDT per animal across all tested sessions. Across all sessions and for eac animal's best session, earplugged animals had higher thresholds than controls (left, EPSil vs (tSil). Stimulus exposure improved thresholds (EPSil vs EPGap), and these remediated thresholds were as low as those of controls (CtSil vs EPGap). In non-EP animals, gap exposure reduced the variability of detection thresholds due to fewer animals with high thresholds (CtSil vs CtGap). Wide blue bars, Medians across three sessions for each group. Thin blue bars, Median for each session or group. NT indicates that the longest gap presented ( $30 \mathrm{~ms}$ ) was not detected. Planned comparisons, ${ }^{* * *} p<0.0002$; unequal variance, ${ }^{\diamond} p<0.005$.

plugs rarely came out, while from P17 to P24, earplugs were found to have come out $2.8 \pm 1.2$ times per animal, with no difference between EPSil and EPGap groups (Mann-Whitney $p=0.4$ ). Earplugs were never out for $>12 \mathrm{~h}$ before reinsertion. Earplugs were maintained for $13 \mathrm{~d}$ and removed on P24. The tympanic membrane was visualized and confirmed to be intact and clear of any residual earplug material. Control groups were sham-treated, receiving identical handling and pinna manipulation (without earplug insertion).

\section{Behavioral testing}

Gap-detection abilities were assessed using prepulse inhibition (PPI) of the acoustic startle response (ASR), where some type of prepulse stimulus that precedes the startling stimulus inhibits the startle response. The strength of inhibition corresponds with an animal's detection of the prepulse. Here, the prepulse was a silent gap in background noise (gapPPI). The procedure has been described previously (Green et al., 2016). Briefly, animals were placed inside a small acoustically transparent restrainer, which was set on a force plate in a sound-attenuated, anechoic booth, with the lights on. Two separate speakers in each booth presented either background bandpass noise at $50 \mathrm{~dB}$ SPL (presented from the front) or a startling stimulus at $110 \mathrm{~dB}$ SPL (presented from the top; Kinder Scientific). The background noise was bandpassed from 2.5 to $20 \mathrm{kHz}$ to match the subultrasonic frequency region most attenuated by the earplugs (Fig. 1B). The startle level was chosen based on measurements of startle-only responses in gerbils of this age; a level of $110 \mathrm{~dB}$ SPL revealed a clear reduction of the ASR as a result of gap-PPI (Longenecker and Galazyuk, 2012; Green et al., 2016). We presented 190 trials in pseudorandom order. Of these, 57 trials were startle-only, with a startle stimulus of $20 \mathrm{~ms}$ broadband noise at $110 \mathrm{~dB}$ SPL, $1 \mathrm{~ms}$ rise/fall time. The remaining 133 were gap trials, where the startle stimulus was preceded by a silent gap in the noise background of either 2, 3, 5, 7, 10, 20, or $30 \mathrm{~ms}$, with 19 trials of each gap duration. Behaviorally in operant setups, gerbils can detect gaps as short as 1-2 ms (Wagner et al., 2003). Therefore, we presented the shortest gap that could be produced by the Kinder Scientific startle software ( $2 \mathrm{~ms}$ ). The background noise preceding and following the gap was shaped with a $1 \mathrm{~ms}$ rise/fall time. At the beginning of each session, five startle-only trials were presented (not included in analysis) to habituate the startle-only and PPI responses to a steady-state level where that function crossed a detection criterion, the transformed startle-only values were sampled with replacement 10,000 times to generate a normal distribution, from which $95 \%$ confidence intervals were calculated. The lower confidence interval was the value where a reduction in startle indicated significant detection (Fechter et al., 1988). GDT was the level at which the fitted detection function crossed the lower confidence interval. Note that this analysis accounts for any inherent variability in startle magnitude within each animal. Group differences were assessed with Kruskal-Wallis (KW) nonparametric ANOVAs followed by Wilcoxon rank-sum tests (equivalent to Mann-Whitney $U$ tests) for preplanned comparisons.

In some instances [Fig. 2, symbols with GDTs of NT (no threshold)] animals were unable to detect any of the experimental gaps, which is not surprising as the longest gap presented was rather short $(30 \mathrm{~ms})$. This occurred most frequently in EPSil animals ( $21 \%$ of sessions), and much less often in the other groups (EPGap, 4\%; CtSil, 10\%; CtGap, $0 \%$ of sessions), suggesting that a lack of PPI to any gap durations presented was a true lack of detection that was treatment-dependent. As confirmation of this likelihood, all animals in the study yielded thresholds within the tested range during $\geq 1$ session (Fig. $2 B$ ). Conservatively, GDTs of $31 \mathrm{~ms}$ were substituted for sessions where gaps were not detected. Those GDTs are represented as NT in Figure 2.

\section{Auditory brainstem responses}

Auditory brainstem responses (ABRs) were measured from separate sets of animals to (1) determine the magnitude of hearing loss induced by acute earplug insertion and (2) measure whether the chronic earplugging affected peripheral function. Animals were anesthetized with ketamine and chloral hydrate and presented with auditory stimuli (RZ6 Auditory Processor, BioSigRP software, Tucker Davis Technologies [TDT]). Responses to individual stimuli were conducted using stainless steel needle electrodes inserted subdermally at the dorsal midline between the eyes (noninverting), posterior to the right pinna (inverting), and base of the tail (common ground), amplified (20×; TDT, low-impedance RA4LI), bandpass filtered $(0.3-3 \mathrm{kHz})$, and digitized $(24.4 \mathrm{kHz}$; TDT, RZ5 BioAmp Processor). Auditory stimuli were $5 \mathrm{~ms}$ pure tones with $1 \mathrm{~ms}$ rise/fall times, repeated at $21 / \mathrm{s}$, presented at $1,2,4,8$, and $16 \mathrm{kHz}$ from a freefield speaker located $7 \mathrm{~cm}$ from the right ear. Responses were aver- 
Table 1. Numbers and proportions across treatment groups of $\mathrm{SU}$ and $\mathrm{MU}$ recordings, and of units categorized based on response to $200 \mathrm{~ms}$ tone at $\mathrm{BF}^{a}$

\begin{tabular}{|c|c|c|c|c|c|c|}
\hline & SUs & MUs & Phasic & Nonphasic & Sustained & Nonsustained \\
\hline Overall $N$ & 203 & 318 & 339 & 182 & 337 & 184 \\
\hline$\%$ CtSil & $37 \%$ & $63 \%$ & $54 \%$ & $46 \%$ & $57 \%$ & $43 \%$ \\
\hline$\%$ EPSil & $34 \%$ & $66 \%$ & $66 \%$ & $34 \%$ & $72 \%$ & $28 \%$ \\
\hline \% EPGap & $40 \%$ & $60 \%$ & $64 \%$ & $36 \%$ & $75 \%$ & $25 \%$ \\
\hline \% CtGap & $51 \%$ & $49 \%$ & $77 \%$ & $23 \%$ & $55 \%$ & $45 \%$ \\
\hline \multicolumn{7}{|c|}{ Neural GDT comparisons } \\
\hline KW ANOVA & $\begin{array}{c}\chi_{(3,199)}^{2}=23.8 ; \\
p<0.0001\end{array}$ & $\begin{array}{c}\chi_{(3,314)}^{2}=19.8 \\
p<0.0003\end{array}$ & $\begin{array}{c}\chi_{(3,335)}^{2}=21.5 \\
p<0.0001\end{array}$ & $\begin{array}{c}\chi_{(3,178)}^{2}=17.4 ; \\
p<0.0006\end{array}$ & $\begin{array}{c}\chi_{(3,333)}^{2}=15.6 \\
p<0.002\end{array}$ & $\begin{array}{c}\chi_{(3,180)}^{2}=26.3 ; \\
\quad p<0.0001\end{array}$ \\
\hline CtSil vs EPSil & $p<0.001$ & $p<0.0002$ & $p<0.0001$ & $p<0.0003$ & $p<0.02$ & $p<0.0004$ \\
\hline EPSil vs EPGap & $p<0.0004$ & $p<0.005$ & $p<0.003$ & $p<0.002$ & $p<0.0002$ & $p=0.05$ \\
\hline CtSil vs EPGap & $p=0.24$ & $p=0.83$ & $p=0.996$ & $p=0.72$ & $p=0.11$ & $p=0.29$ \\
\hline
\end{tabular}

${ }^{a}$ Comparisons of neural GDTs for each of the four categories and separately for SUs and MUs.

aged over 300 presentations. Sound level was adjusted in $5 \mathrm{~dB}$ steps to obtain a threshold response (i.e., a visually detectable N1 potential).

\section{Surgical preparation}

Gerbils were premedicated with buprenorphine $(0.5 \mathrm{mg} / \mathrm{kg}$, i.p. $)$ and dexamethasone $(0.35 \mathrm{mg} / \mathrm{kg}$, i.p.) and hydrated with normosol $(1.5 \mathrm{ml}$, s.c.). The animals were anesthetized with isoflurane and held in a stereotaxic apparatus. A small headpost was positioned along the midline and secured with dental acrylic. A silver ground wire was implanted into the posterior contralateral skull. Using stereotaxic coordinates, a craniotomy was made over the left temporal cortex caudal to the bregma suture (Thomas et al., 1993), and the dura was left intact. A thin well of dental acrylic was fashioned along the perimeter of the craniotomy, the cortical surface was covered with silicone oil, and the craniotomized area was covered with a disposable cap of silicone elastomer (Matrics Inc, ImageLB28). The entire skull was covered with dental acrylic to form a headcap.

\section{Neurophysiological recordings}

On the day of recording, animals were anesthetized with urethane $(1.3 \mathrm{~g} / \mathrm{kg}$, administered in two doses over $1.5 \mathrm{~h})$ and placed in a soundproof chamber (Industrial Acoustics) on a heating pad. The head was stabilized using the headpost, the silicone elastomer cap removed, and the dura was covered with saline during recording to maintain moisture. Platinum-plated tungsten electrodes (1.5-2.5 M $\Omega$; MicroProbe) were advanced ventrally through the craniotomy with an electrode tip angle of $13^{\circ}$ lateral to vertical to isolate neurons in the primary $\mathrm{ACx}$ based on response characteristics (reliable, short-latency, nonadapting responses to tones). TDT equipment was used to record the neural signals. Electrical signals from the brain were amplified (250×; RA16PA preamplifier), filtered $(0.25-10 \mathrm{kHz})$, and digitized $(24.4 \mathrm{kHz}$; RZ5 BioAmp Processor). The TDT equipment was controlled by custom software written in Matlab and TDT RPvdsEx programming environments (TytoLogy by S.J. Shanbhag). Units were isolated by spike amplitude. Spikes were detected off-line (Plexon Offline Sorter), and sorted into single units (SUs) or multiunits (MUs) based on spike shape and principal component analysis. Effects of treatment on neural GDTs were consistent when analyzed separately for either just SUs or just MUs (Table 1), so SUs and MUs were pooled for all analyses.

\section{Acoustic stimulation for neurophysiology}

TDT equipment (RZ6 Auditory Processor) was used to deliver auditory stimuli. Custom software written in Matlab and TDT RPvdsEx (TytoLogy by S.J. Shanbhag; modified by M.J. Rosen) generated stimuli, controlled TDT equipment, and coordinated auditory stimuli with neural recordings. Auditory stimuli over a frequency range of $200 \mathrm{~Hz}$ to $35 \mathrm{kHz}$ were calibrated using custom software written in Matlab (S.J. Shanbhag). Calibration data were collected using a one-quarter inch microphone (Brüel and Kjær, model 4939), a preamplifier (Brüel and Kjær, model 2670) and a conditioning amplifier (Brüel and Kjær, Nexus model 2690). Stimuli were delivered through a freefield speaker positioned $25 \mathrm{~cm}$ in front of the animal.

To measure responses to static tones, neurons were presented with tone pips (200 ms, $5 \mathrm{~ms}$ cosine-ramped rise/fall). First, the frequency range over which the neuron was responsive was obtained with an isointensity function at $60 \mathrm{~dB}$ SPL. This was followed by a rate-level function (RLF) at the best frequency (BF) of the unit, measured at increments of $10 \mathrm{~dB}$ SPL, for $10-15$ trials (with a $1 \mathrm{~s}$ intertrial interval). Threshold was visually determined as $5 \mathrm{~dB}$ below the lowest level with a clear increase in spiking above lower levels. A gap-detection function was obtained at the $\mathrm{BF}$ of the unit and $30 \mathrm{~dB}$ above threshold, with 20 trials at each gap duration, presented in random order. Gap-detection stimuli consisted of two consecutive tone bursts lasting a total of $400 \mathrm{~ms}$ (with $5 \mathrm{~ms}$ cosineramped rise/fall). The bursts were separated by gaps of varying durations $(0,1,2,3,5,7,10,15,25$, or $50 \mathrm{~ms}$ with a $0.5 \mathrm{~ms}$ cosine-ramped rise/fall $)$ inserted between the two bursts at $200 \mathrm{~ms}$ after the onset of the first burst. This range was chosen to span the gap durations presented behaviorally, with the $50 \mathrm{~ms}$ gap presented to measure less gap-responsive neurons. The 0 ms gap stimulus was the control against which gap detection was measured, and thus did not contain rise/fall ramps at $200 \mathrm{~ms}$, but was instead a continuous $400 \mathrm{~ms}$ tone burst. This control was chosen to mimic the behavioral stimuli, where detection of gaps in background noise is determined in comparison to continuity in the background noise. After collecting the gap-detection tone function, the unit was presented with $200 \mathrm{~ms}$ bursts of noise at $50 \mathrm{~dB}$ SPL, bandpassed from 2.5 to $20 \mathrm{kHz}$, to match the background noise used for the behavioral testing. If the unit showed a clear response to the noise (true for approximately half the units tested), a noise gap detection function was obtained with 20 trials at each gap duration, presented in random order.

\section{Neural data analysis}

Rate-level functions. Firing rates to tones were calculated over a time window equal to the stimulus duration. Threshold, dynamic range, and monotonicity were determined from the RLF. Threshold was defined as the $\mathrm{dB}$ SPL level at which there was a $\geq 35 \%$ increase in firing rate, stepping up from one $\mathrm{dB}$ SPL level to the next; threshold firing rates were calculated at this sound level. Dynamic range was defined as the range between the dB SPL levels where each cell responded at 10 and $90 \%$ of its maximum firing rate, calculated by interpolation. To allow valid comparisons, RLF data were collected using equivalent ranges of levels across all groups (0-80 dB SPL). Group differences for each of these were assessed with KW nonparametric ANOVAs followed by Wilcoxon ranksum tests for preplanned comparisons. Nonmonotonic neurons were defined as those whose firing rates at the highest $\mathrm{dB}$ SPL tested dropped below $75 \%$ of their maximum firing rate. Group differences for monotonicity were assessed using $\chi^{2}$. All data were analyzed with custom Matlab scripts (M.J. Rosen). In boxplots, box edges are 25th and 75th percentiles, with whiskers extending to the most extreme data points, excluding outliers.

Gap detection. Responses to each gap duration were measured from poststimulus time histograms (PSTHs) with $5 \mathrm{~ms}$ bins calculated across the 20 trials. Only units with onset responses to the first burst of the gap-detection stimuli were used for gap-detection analysis. A valid onset response (within $100 \mathrm{~ms}$ following the first burst) was determined as spiking $20 \%$ of the time within a single bin across trials. A valid gap response (within $100 \mathrm{~ms}$ following the second burst) was determined 
based on the bin with maximal firing in this window. After subtracting baseline firing (calculated in the same window when no gap was present), a response in the peak bin $20 \%$ of the time was considered a valid gapdetection response. The shortest duration gap with a valid gap-detection response was considered the GDT (Eggermont, 2000). If a significant response to the second burst was absent for all gap durations, a GDT of $60 \mathrm{~ms}$ was assigned (since only cells with valid onset responses were analyzed, a gap longer than the longest presented would necessarily elicit a response). First spike latency (FSL) and FSL jitter were measured directly from spike timing rather than from binned PSTHs, and were based on the onset response to the first burst. All data were analyzed with custom Matlab scripts (M. Rosen and D. Green). In boxplots, box edges are 25th and 75th percentiles, with whiskers extending to the most extreme data points, excluding outliers.

Ideal observer analysis. An ideal observer model was used to determine how well the combined information across the population of neural units could discriminate between gap and no-gap trials. By definition, an ideal unbiased observer performs a given task optimally, maximizing hits and minimizing false-alarm rates, given the information available (Geisler, 2011). We compared the ideal observer's ability to detect gaps of varying durations. We trained a support vector machine and ran a 10 -fold crossvalidation on this trained classifier. Specifically, we used $85 \%$ of the neural data for training, while testing the model's performance on the remaining $15 \%$ of the neural data, separately for each of the four experimental groups. We trained and tested the model with trial-by-trial firing rates from $100 \mathrm{~ms}$ time windows following each gap offset. The classifier, implemented in Matlab 2016, used custom scripts (M.J. Rosen, Y.E. Cohen, and A. Ihlefeld) that trained a binary support vector machine classifier (fitcsvm in Matlab) and tested the performance on the remainder of the data by computing a loss estimate using cross-validation (crossval in Matlab). Equal numbers of neurons were used across the four experimental groups, limited by the group with the fewest units that had valid onset responses to the first burst ( 88 units for trials with tone carriers at BF; 70 units for trials with bandpass noise carriers). The crossvalidated model was run 100 times to generate mean performance with SEM error bars.

Response type classification. Cells varied in how phasic their onset responses were, and how much of a sustained response they exhibited. We categorized populations within the four treatment groups by response type: SUs and MUs were categorized as phasic versus nonphasic, and as sustained versus nonsustained, based on the response to a tone at BF, calculated from PSTHs with $5 \mathrm{~ms}$ bins. To determine phasic/nonphasic categorization, we looked within the first $50 \mathrm{~ms}$ of the response, and measured "peak" firing rate within the $15 \mathrm{~ms}$ window surrounding the bin with maximal firing. If this peak firing rate exceeded baseline firing by a factor of 6 , and returned to $25 \%$ of peak firing during the next $15 \mathrm{~ms}$, the unit was categorized as phasic. Otherwise, it was categorized as nonphasic. The baseline firing rate was calculated from $100 \mathrm{~ms}$ of spontaneous activity preceding the tone. To determine sustained/nonsustained categorization, we measured firing rate over the first $150 \mathrm{~ms}$ of the response. If this exceeded baseline firing by a factor of 2 , the unit was categorized as sustained. Otherwise, it was categorized as nonsustained. Table 1 shows the number of units classified as phasic, nonphasic, sustained, and nonsustained across all cells, and percentages of cells in each of these categories for each treatment group. Across experimental groups, there were no systematic shifts in response type. Within each category, effects of treatment on GDTs (Table 1, bottom) were consistent with responses collapsed across response type (see Results). Thus, for the remainder of this study, we examined all onset-responsive cells in each experimental group.

\section{Results}

\section{Earplug-induced attenuation}

To determine the magnitude of attenuation induced by acute earplug insertion, ABRs were measured from seven animals (P33-P46) separate from the experimental groups (Fig. 1B). ABRs were measured before and during bilateral earplug insertion. A two-way ANOVA revealed main effects of frequency $\left(F_{(1,4)}=12.9, p<\right.$
$0.0001)$ and earplugging $\left(F_{(1,4)}=264.8, p<0.0001\right)$. Post hoc tests showed that earplugging significantly raised thresholds at all frequencies tested (Bonferroni-corrected post hoc tests, all p's $<$ 0.04). A significant interaction between frequency and earplugging was due to greater attenuation at higher frequencies, with shifts ranging from $13.6 \mathrm{~dB}$ at $1000 \mathrm{~Hz}$ to $35.7 \mathrm{~dB}$ at $8000 \mathrm{~Hz}$ $\left(F_{(1,4)}=4.8, p<0.002\right)$.

\section{Behavioral gap detection is impaired by early hearing loss}

To determine whether early transient hearing loss affected gap detection, animals were earplugged from P11 to P24 (i.e., from before hearing onset to after the closure of known ACx critical periods; Mowery et al., 2015). They were compared with sham controls who were handled equivalently, to control for potential effects of early stress on later gap-detection abilities (Green et al., 2016). After earplug removal, both groups experienced silence in the testing enclosure for three $1 \mathrm{~h}$ sessions (Fig. 1A, top). At P33, P36, and P39, animals were tested for GDTs using gap-PPI of the ASR.

In Figure 2, GDTs are plotted separately for each group, for each of the three sessions, and for each animal's best performance regardless of session. Across all three sessions, earplugging significantly impaired gap-detection ability (Fig. 2A, circles; KW ANOVA: $\chi_{(3,251)}^{2}=42.3, p<0.0001$; Mann-Whitney EPSil vs CtSil: $p<$ $0.0001)$. Animals improved with testing, such that on the third session, GDTs of EPSil animals were not significantly different from those of CtSil animals (KW ANOVA: $\chi_{(3,251)}^{2}=8.4, p<0.04$; Mann-Whitney EPSil vs CtSil: $p=0.1$ ). However, even the best performance of individual animals across sessions was impaired by early deprivation (Fig. $2 B$, circles; KW ANOVA: $\chi_{(3,81)}^{2}=8.4, p=$ 0.038; Mann-Whitney EPSil vs CtSil: $p<0.002$ ).

\section{Behavioral gap detection is fully remediated by brief stimulus exposure}

We have previously shown that brief, unattended exposure to background noise with gaps produces learning in control animals (Green et al., 2016). Here, we tested whether the plasticity induced by these short periods of gap-only exposure could remediate behavioral gap-detection deficits induced by early hearing loss. In two additional groups, animals were earplugged or shamtreated identically to the silence-exposed groups (Fig. 1A, bottom). After earplug removal, both groups were placed in the testing enclosure and exposed to three $1 \mathrm{~h}$ sessions of background noise with intermittent gaps. At P33, P36, and P39, animals were tested for GDTs using gap-PPI of the ASR.

Across all three sessions, gap exposure significantly improved performance of earplugged animals (Fig. 2A, orange symbols; EPSil vs EPGap: $p<0.0002$ ). Notably, across the sessions, remediated performance of EPGap animals was as good as that of CtSil animals (Fig. 2A, gray circles vs orange diamonds; Mann-Whitney CtSil vs EPGap: $p=0.3$ ). This drop in GDTs to levels indistinguishable from those of controls was also visible based on the best performance of individuals across sessions (Mann-Whitney EPSil vs EPGap: $p<0.05$; Mann-Whitney CtSil vs EPGap: $p=$ $0.4)$. Finally, there was a reduction in GDT variability with stimulus exposure, due to more animals achieving low thresholds (Levene's test for unequal variances, EPSil vs EPGap: across sessions $F_{(1,130)}=10.1, p=0.002$; best session $F_{(1,42)}=7.8, p=$ 0.008 ). Thus, brief stimulus exposure was sufficient to fully remediate behavioral GDTs in earplugged animals. 
ACx gap detection is worsened by early hearing loss

Detection of short gaps as assessed by gap-PPI requires the ACx, as demonstrated by inactivation experiments (Ison et al., 1991; Threlkeld et al., 2008), and the ACx is a known site of plasticity that reflects early auditory experience (Kral and Eggermont, 2007; Takesian et al., 2009; Rosen et al., 2012). We thus tested whether GDTs in ACx neurons worsened with early earplugging, as a possible substrate for the increased behavioral GDTs. During the week following the last behavioral testing session, we recorded gap-detection functions (with a carrier at each neuron's BF) from 136 and 180 SUs and MUs in CtSil and EPSil animals, respectively (Table 1). Figure 3 contains examples of four different gapresponsive units to represent the variability of response types and to show different GDTs (stars). Gap detection was measured based on firing immediately following gap offset.

In silence-exposed groups, early transient hearing loss significantly worsened neural GDTs compared with controls (Fig. 4A, circles; KW ANOVA: $\chi_{(3,517)}^{2}=36.8, p<0.0001$; Mann-Whitney EPSil vs CtSil: $p<0.0001)$. Plotting the distribution of neural GDTs for these two groups (Fig. $4 B$ ) reveals a clear shift in earplugged animals: more cells without gap responses at the longest gap duration tested, and fewer cells with short GDTs, compared with CtSil animals (solid orange vs gray bars). The peak firing rates used to calculate these GDTs increase with longer gaps (Fig. $4 E$; two-way ANOVA, main effect of gap duration: $F_{(3,8)}=44.1$, $p<0.0001)$, as the response fully recovers from the response to the leading tone burst (Eggermont, 2000). Earplugged animals had reduced cortical firing following gap offset compared with controls (Fig. 4E; two-way ANOVA, main effect of group: $F_{(3,8)}=$ 61.5, $p<0.0001$; Bonferroni post hoc EPSil vs CtSil: $p<0.0001)$. Earplugged animals also had a marginally smaller dynamic range of response than control animals, as seen by comparing peak firing rates at shortest versus longest gaps (Fig. 4E; solid orange vs gray bars; Mann-Whitney EPSil vs CtSil: $p=0.09$ ). Both these elements of peak firing to gap offset would contribute to the higher GDTs in earplugged animals.

\section{ACx gap detection is fully remediated by brief} stimulus exposure

Cortical gap-detection functions were also measured in stimulusexposed animals following the last behavioral session (88 SUs and MUs in EPGap animals and 117 SUs and MUs in CtGap animals; Table 1). Cortical GDTs from stimulus-exposed earplugged animals were better than those of unexposed earplugged animals (Fig. 4A, orange symbols; Mann-Whitney EPSil vs EPGap: $p<$ $0.0001)$. This was a full remediation, as the GDTs did not differ from those of unexposed control animals (Fig. 4A, gray circle vs orange diamond; Mann-Whitney CtSil vs EPGap: $p=0.7$ ). Brief stimulus exposure also shifted the distribution of GDTs in earplugged animals, reducing the number of cells without gap responses at the longest gap duration tested, and increasing the number of cells with sensitive GDTs (Fig. 4C, solid vs open bars). This shift was accompanied by a change in the peak firing rates used to calculate GDTs (Fig. $4 F$ ). Stimulus exposure increased the cortical firing following gap offset (Bonferroni post hoc EPSil vs EPGap: $p<0.0001$ ), and increased the dynamic range of response across gap durations, based on comparing peak firing rates at shortest versus longest gaps (Fig. $4 F$, solid vs open bars; Mann-Whitney EPSil vs EPGap: $p<0.0002$ ).

It has been shown that the cortical responses at gap offset directly influence gap detection measured by gap-PPI (Weible et al., 2014). Thus, a model trained with these responses should reflect behavioral GDTs, showing poorer detection at shorter
A Phasic/Nonsustained

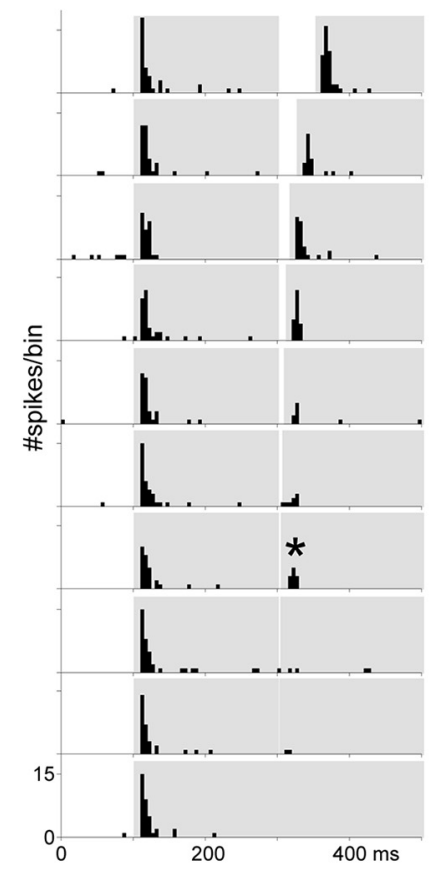

B Phasic/Sustained

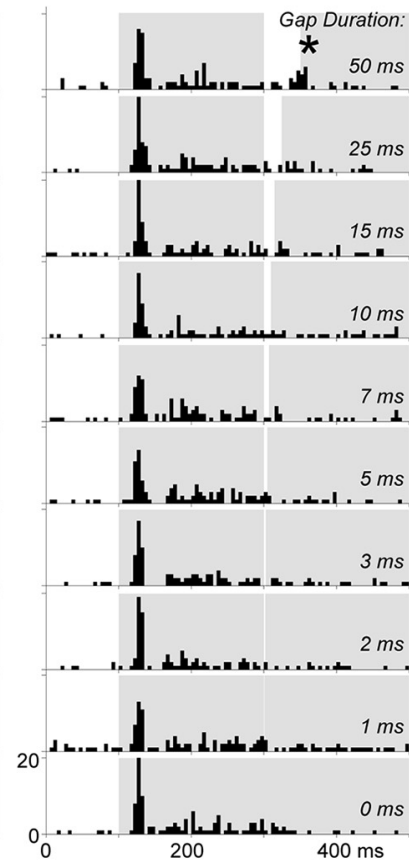

C Nonphasic/Nonsustained

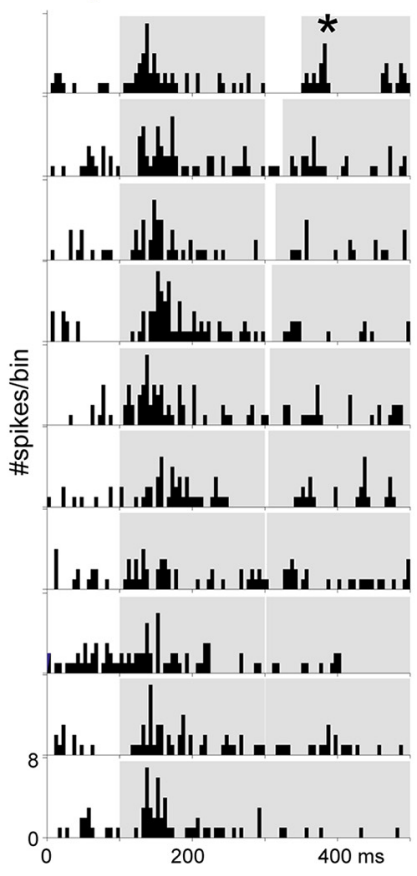

\section{Nonphasic/Sustained}

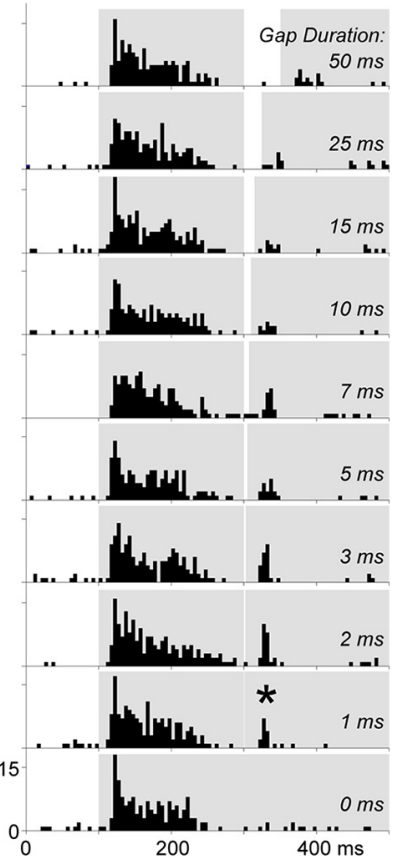

Figure 3. Examples of $A C x$ neuron response types to gaps in tones. $A-D$, Examples of neurons classified as $(\boldsymbol{A})$ phasic onset without a sustained response, $(\boldsymbol{B})$ phasic onset with a sustained response, $(\boldsymbol{C})$ nonphasic onset without a sustained response, and $(\boldsymbol{D})$ nonphasic onset with a sustained response. PSTHs show responses to 20 trials of tones with gaps inserted at 300 $\mathrm{ms}$, for gap durations ranging from 50 to $0 \mathrm{~ms}$. Gray regions overlying each PSTH represent the time course of the two tone bursts and the gap between them. Stars indicate the shortest gap duration at which a response was detected. The neurons were from EPSil, CtSil, CtGap, and EPGap groups, respectively, although there was no pattern of response type based on group (Table 1).

gaps. Furthermore, the performance of that model should follow the behavioral shifts seen across the experimental groups: worsening with earplugging and improving with stimulus exposure. To test these predictions, we used an ideal observer model to 

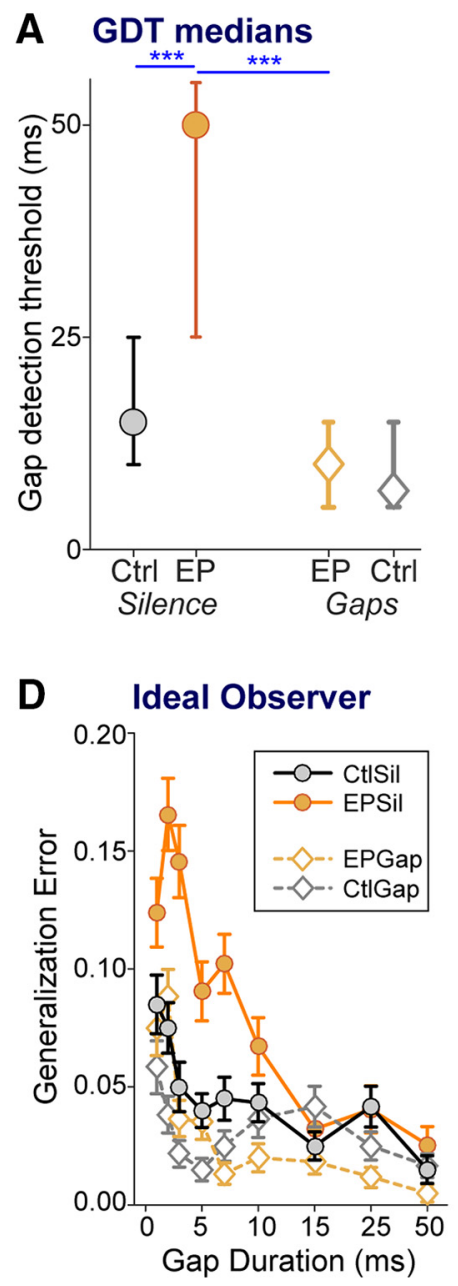

B GDT distribution:

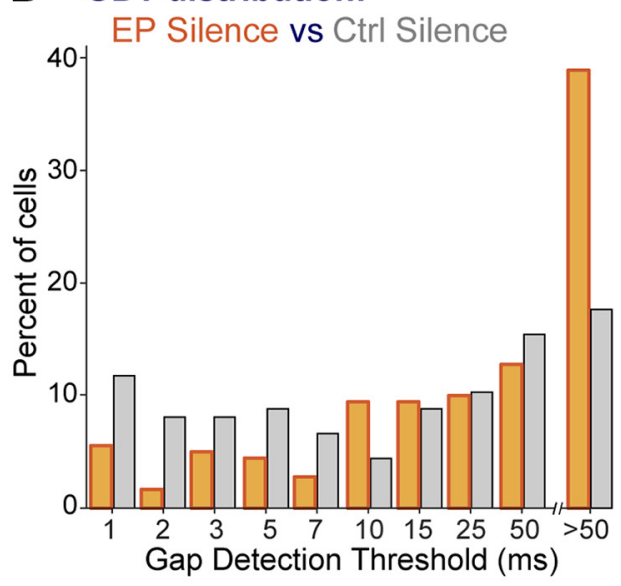

E Peak FR after gap vs baseline:

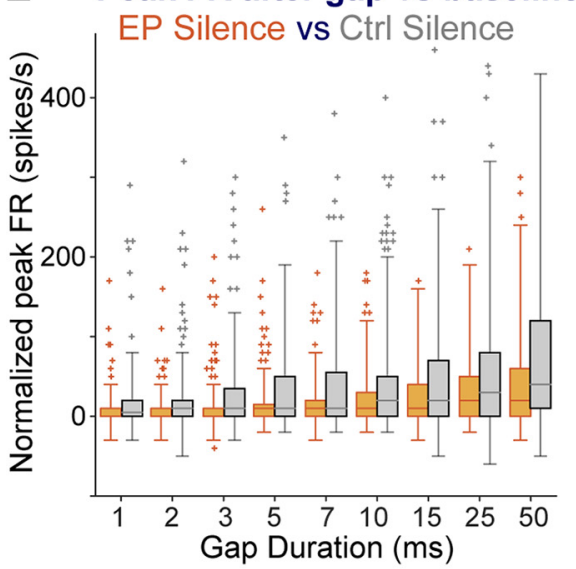

\section{GDT distribution:}
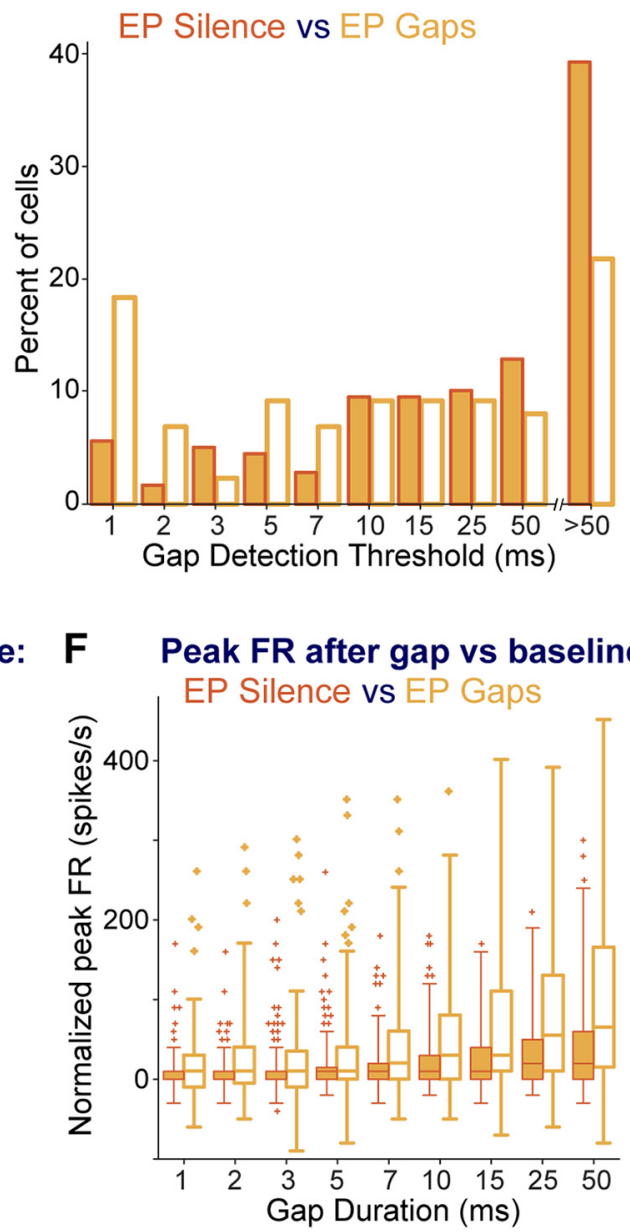

Figure 4. Cortical GDTs are worsened by early hearing loss, and remediated to control levels by stimulus exposure. $\boldsymbol{A}$, Median GDTs (with $95 \%$ confidence intervals). $\boldsymbol{B}$, For silence-exposed animals, distribution of GDTs of groups with and without earplugs, showing that the difference in median GDT reflects earplugged animals having fewer cells with low GDTs and more cells with high GDTs. C, For earplugged animals, distribution of GDTs of groups with and without stimulus exposure, showing that the difference in median GDT reflects remediated animals having more cells with low GDTs and fewer cells with high GDTs. D, The function generated by an ideal observer model plots the error made by the model for correctly detecting gaps of specific durations, based on the firing rate in the window immediately following the gap. The ideal observer model predicts reduced sensitivity with increasing gap durations. Furthermore, for short gap durations of $<15 \mathrm{~ms}$, the ideal observer model reveals poorer performance for the EPSil neurons compared with the other three groups. Error bars are SEM based on 100 runs of the model. $\boldsymbol{E}$, $\boldsymbol{F}$, Across gap durations, boxplots of peak firing rates (FRs) within the time window following each gap, allowing comparisons between $(\boldsymbol{E})$ CtSil and EPSil groups and $(\boldsymbol{F})$ EPSil and EPGap groups. These peak FRs are the values used to generate the analyses in $\boldsymbol{A}-\boldsymbol{D}$. Planned comparisons: ${ }^{* * *} p<0.0002$.

determine how well the combined information across the population of neural units could discriminate between gap and no-gap trials, and whether this population discrimination performance predicted behavioral differences across the groups. Here, we compared the ideal observer's ability to detect gaps of varying durations for each of the four groups (Fig. 4D). As suggested by the behavior, the model predicts greater error distinguishing short-gap responses from no-gap responses for all groups. The model further predicts greater errors detecting short duration gaps $(<15 \mathrm{~ms})$ in the EPSil group than in controls and remediated groups. The model is thus consistent with behavioral gapdetection abilities across the experimental groups.

Temporal coding elements in cortical neurons are degraded by early hearing loss, and fully remediated by brief stimulus exposure

Early auditory deprivation is known to impair aspects of temporal processing aside from gap detection both behaviorally and in ACx neurons (Rosen et al., 2012; Caras and Sanes, 2015). We thus expected earplugging to more broadly affect cortical temporal processing elements, and examined whether brief stimulus exposure would shift those elements to control levels. We measured FSL and FSL jitter across trials in response to the onset burst of the gap stimuli. Both FSL and FSL jitter were increased by earplugging (Fig. $5 A, B$, circles; FSL KW ANOVA: $\chi_{(3,517)}^{2}=29.2$, $p<0.0001$; Mann-Whitney EPSil vs CtSil: $p<0.002$; FSL jitter KW ANOVA: $\chi_{(3,517)}^{2}=48.8, p<0.0001$; Mann-Whitney EPSil vs CtSil: $p<0.0003)$. Stimulus exposure reduced both FSL and FSL jitter (Fig. $5 A, B$, orange symbols; Mann-Whitney EPSil vs EPGap: FSL $p<0.0001$, FSL jitter $p<0.0001)$. Stimulus exposure fully remediated earplugged animals' FSLs to control levels, and reduced FSL jitter to a precision even better than that of controls (Fig. 5A, $B$, gray circles vs orange diamonds; MannWhitney CtSil vs EPGap: FSL $p=0.6$, FSL jitter $p<0.02$ ).

We tested whether the effects of earplugging and stimulus exposure affected general temporal processing in highly gapsensitive neurons, i.e., the subset with GDTs $\leq 10 \mathrm{~ms}$. This included 65, 52, 46, and 68 neurons respectively in CtSil, EPSil, EPGap, and CtGap animals. All the relationships described above for the population of cells were maintained in this subset of cells. 
$A_{\text {FSL }}$

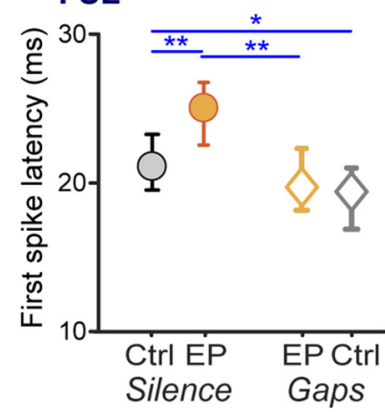

C FSL: Best GDT cells



B FSL jitter

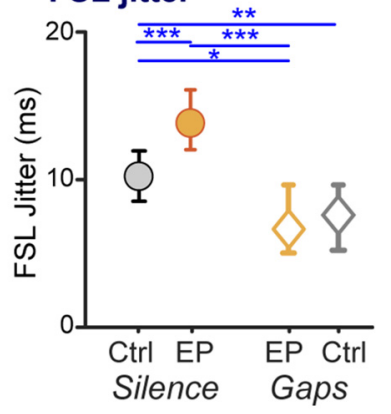

D FSL jitter: Best GDT cells

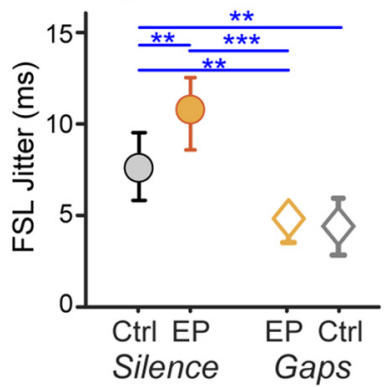

Figure 5. Temporal coding is altered by early hearing loss, and remediated to control levels by stimulus exposure. FSLs and the precision of first spikes were measured from responses to the initial tone burst of GDT functions. $\boldsymbol{A}-\boldsymbol{D}$, FSLs and FSL jitter are depicted across groups for $(\boldsymbol{A}, \boldsymbol{B})$ all neurons and $(\boldsymbol{C}, \boldsymbol{D})$ neurons with high sensitivity to gaps (GDTs, $\leq 10 \mathrm{~ms})$. Earplugging increased FSL and FSL jitter in all cells as well as in the subset of highly gap-sensitive cells. FSL was remediated to levels matching those of controls, while FSL jitter in earplugged animals was reduced to levels even lower than that of controls after remediation. Finally, FSL jitter was reduced by stimulus exposure even in control animals. Planned comparisons: ${ }^{*} p<0.03 ;{ }^{* *} p<$ $0.008 ;{ }^{* *} p<0.0005$. All plots show medians with $95 \%$ confidence intervals.

Both FSL and FSL jitter were increased by earplugging (Fig. 5C, $D$, circles; FSL KW ANOVA: $\chi_{(3,227)}^{2}=22.7, p<0.0001$; MannWhitney EPSil vs CtSil: $p<0.004$; FSL jitter KW ANOVA: $\chi_{(3,227)}^{2}=33.3, p<0.0001$; Mann-Whitney EPSil vs CtSil: $p<$ 0.007). Stimulus exposure reduced FSL and FSL jitter (Fig. $5 C, D$, orange symbols; Mann-Whitney EPSil vs EPGap: FSL $p<$ 0.0005 , FSL jitter $p<0.0001)$. Finally, stimulus exposure fully remediated earplugged animals' FSLs to control levels, and reduced FSL jitter to yield more precise firing than that of controls (Fig. 5C,D, gray circles vs orange diamonds; Mann-Whitney CtSil vs EPGap: FSL $p=0.3$, FSL jitter $p<0.008$ ).

General response properties in cortical neurons are altered by early hearing loss, and fully remediated by brief stimulus exposure

Nontemporal elements of cortical auditory processing can also be altered by early auditory deprivation (Takahashi et al., 2006; Rosen et al., 2012). We thus quantified the effects of early deprivation on basic cortical response properties in our animals, then assessed whether brief stimulus exposure returned these response properties to control levels. These properties were assessed from rate-level functions collected from the majority of cortical units used for gap measurements (CtSil $n=135$, EPSil $n=177$, EPGap $n=87$, CtGap $n=111$ ), and are depicted in Figure 6. All groups had somewhat more monotonic than nonmonotonic cells, but the proportions were not affected by treatment (Fig. $6 A ; \chi^{2}$ test: $\chi^{2}=2.07, p=0.7$ ). Dynamic range and threshold (both sound level and firing rate at that level) were reduced by earplugging and remediated to control levels by brief stimulus exposure (dynamic

A Monotonicity

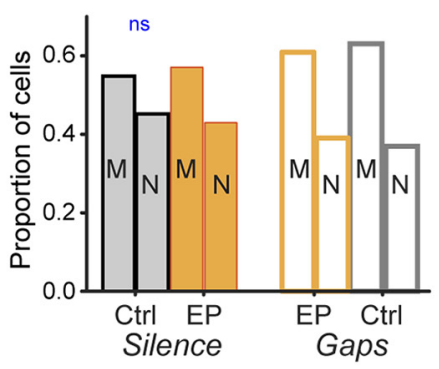

\section{Threshold dB}

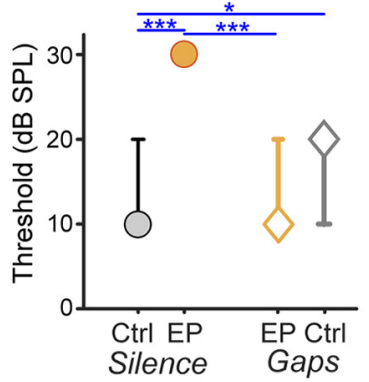

E Spont FR

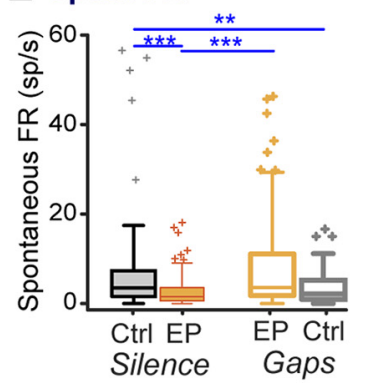

B Dynamic Range

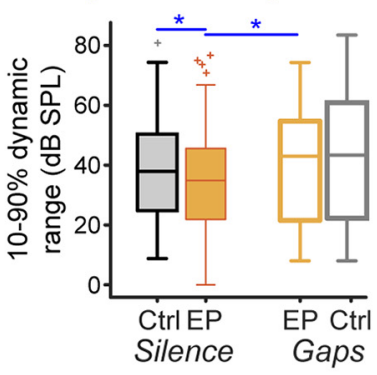

D Threshold FR

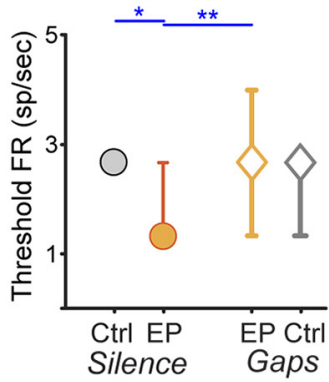

F Evoked FR

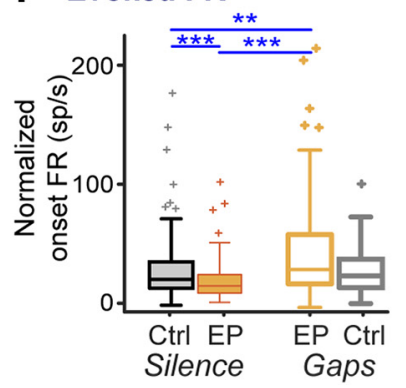

Figure 6. Basic stimulus response properties are altered by early hearing loss, and remediated to control levels by stimulus exposure. $\boldsymbol{A}$, Proportions of monotonic and nonmonotonic cells did not differ across groups. $\boldsymbol{B}$, Dynamic range of neural responses (calculated from ratelevel functions) was reduced by earplugs and raised by stimulus exposure to levels matching those of controls. C, Despite removal of earplugs 14 d earlier and despite normal ABR thresholds and amplitudes, individual cortical threshold levels were higher in earplugged animals and returned to levels of controls after stimulus exposure. $\boldsymbol{D}$, This was accompanied by reduced threshold firing rates in earplugged animals, which returned to levels of controls after stimulus exposure. $\boldsymbol{E}, \boldsymbol{F}$, This phenomenon of reduced and remediated firing rates was recapitulated in both $(\boldsymbol{E})$ spontaneous firing rate during baseline and $(\boldsymbol{F})$ evoked firing rate during responses to the initial tone burst from GDT functions. Line-symbol plots show medians with $95 \%$ confidence intervals. Planned comparisons: ${ }^{*} p<0.05 ;{ }^{* *} p<0.009 ;{ }^{* * *} p<0.0001$.

range; Fig. $6 B$; KW ANOVA: $\chi_{(3,506)}^{2}=10.1, p=0.018$; MannWhitney: EPSil vs CtSil: $p<0.05$; EPSil vs EPGap: $p<0.04$; CtSil vs EPGap: $p=0.6$; threshold decibels, Fig. 6C: KW ANOVA: $\chi_{(3,506)}^{2}=34.0, p<0.0001$; Mann-Whitney: EPSil vs CtSil: $p<$ 0.0001; EPSil vs EPGap: $p<0.0001$; CtSil vs EPGap: $p=0.99$; threshold firing rate; Fig. $6 D$; KW ANOVA: $\chi_{(3,506)}^{2}=9.8, p=$ 0.021; Mann-Whitney: EPSil vs CtSil: $p<0.02$; EPSil vs EPGap: $p<0.009$; CtSil vs EPGap: $p=0.64$ ). Both spontaneous and evoked firing rates (measured in response to the onset burst of the gap stimuli) were decreased by earplugging and remediated to control levels or better (spontaneous firing rate; Fig. 6E; KW ANOVA: $\chi_{(3,517)}^{2}=45.0, p<0.0001$; Mann-Whitney, EPSil vs CtSil: $p<$ 0.0001; EPSil vs EPGap: $p<0.0001$; CtSil vs EPGap: $p=0.19$; evoked firing rate; Fig. 6F; KW ANOVA: $\chi_{(3,517)}^{2}=49.8, p<$ 0.0001; Mann-Whitney, EPSil vs CtSil: $p<0.0001$; EPSil vs EPGap: $p<0.0001$; CtSil vs EPGap: $p<0.002$ ). Thus, early 
A GDT medians Noise B GDT distribution Noise:
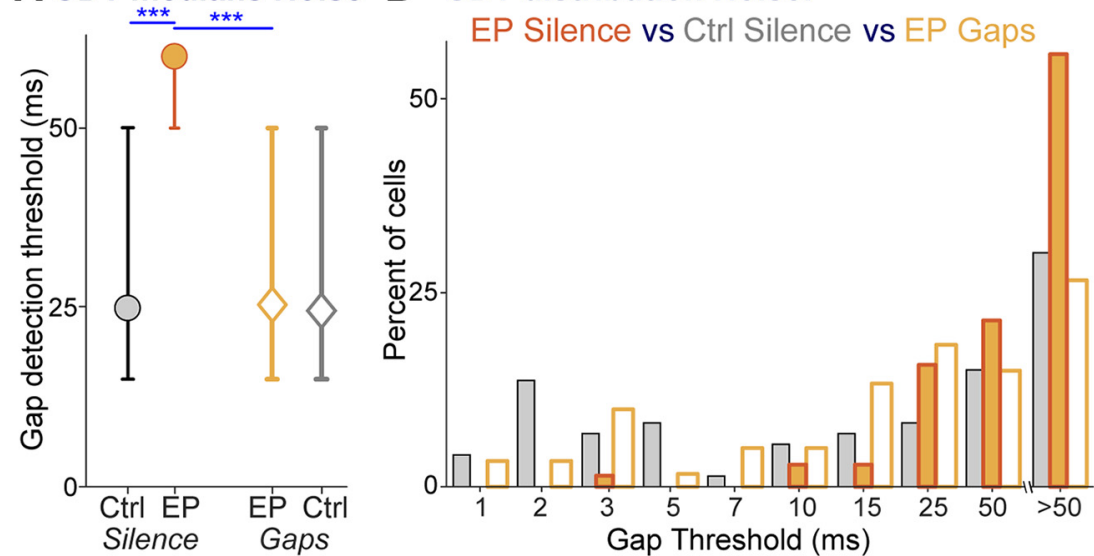

C FSL Noise

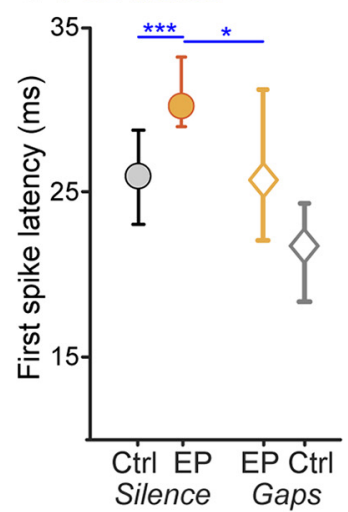

D FSL jitter Noise

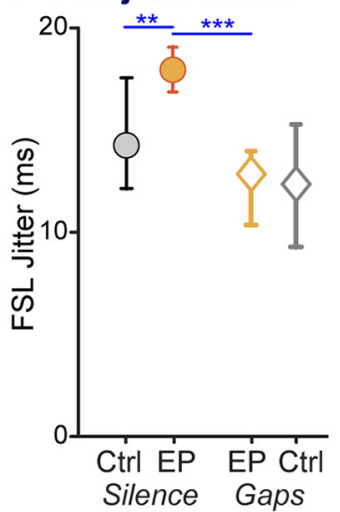

E Ideal Observer: Noise

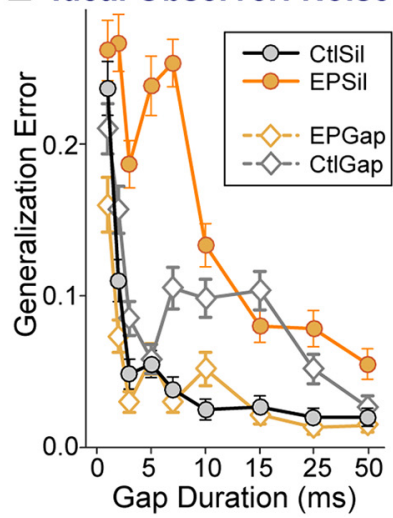

Figure 7. Neurons responsive to bandpass noise also demonstrate effects of hearing loss and remediation. $\boldsymbol{A}$, Median GDTs across groups. $\boldsymbol{B}$, Distributions of GDTs for CtSil, EPSil, and EPGap groups, showing that EPSil animals have fewer cells with low GDTs and more with high GDTs than control or remediated animals. C, D, FSL (C) and (D) FSL jitter were both increased by earplugging and were remediated by stimulus exposure to levels the same as those of controls. $\boldsymbol{E}$, The function generated by an ideal observer model plots the error made by the model for correctly detecting gaps of specific durations. The model predicts reduced sensitivity with increasing gap durations. Furthermore, for short gap durations, the ideal observer model reveals poorer performance for the EPSil neurons compared with the other three groups. Error bars are SEM based on 100 runs of the model. Line-symbol plots in other panels show medians with $95 \%$ confidence intervals. Planned comparisons: ${ }^{*} p<0.01 ;{ }^{* *} p<0.002 ;{ }^{* * *} p<0.0004$.

deprivation has effects on a range of basic response properties, all of which are effectively remediated by brief exposure to gap stimuli.

Neurons responsive to the bandpass noise used in the behavioral tests also demonstrate effects of early hearing loss and remediation by brief stimulus exposure

We performed a more direct test to assess the neural substrate for the behavioral changes in GDTs. Gap-detection functions with a bandpass noise carrier were obtained from the subset of units responsive to this noise (equivalent to that used for the behavioral testing). This yielded 73, 70, 61, and 61 units respectively in CtSil, EPSil, EPGap, and CtGap animals. All changes visible with tonecarrier GDTs were also present with noise carriers. Early transient hearing loss significantly increased neural GDTs, and stimulus exposure remediated GDTs to control levels (Fig. 7A; KW ANOVA: $\chi_{(3,261}^{2}=37.6, p<0.0001$; Mann-Whitney, EPSil vs CtSil, circles: $p<0.0001$; EPSil vs EPGap, orange symbols: $p<0.0001$; CtSil vs EPGap, gray circle vs orange diamond: $p=0.6$ ). As seen for tone-carrier GDTs, the distribution of noise-carrier GDTs shifted with earplugging to more gap-insensitive cells and fewer gapsensitive cells, and shifted back with stimulus exposure (Fig. 7B). The dynamic range of peak firing rates after gap offsets (calcu- lated by comparing peak firing rates at shortest vs longest gaps) shifted by treatment similarly to tone-carrier GDTs. Earplugged animals had a smaller dynamic range of gap response than control animals, but stimulus exposure increased this dynamic range to the same level as controls (data not shown; Mann-Whitney EPSil vs CtSil: $p<0.004$; EPSil vs EPGap: $p<0.0015$; CtSil vs EPGap: $p=0.4$ ). The ideal observer model performed similarly with noise-carrier GDTs as with tonecarrier GDTs (Fig. 7E). That is, more errors occurred distinguishing short-gap responses from no-gap responses, for all groups, and more errors occurred detecting short-duration gaps $(<15 \mathrm{~ms})$ in the EPSil group than in controls and remediated groups. Finally, the general temporal processing changes seen with onset responses to tone carriers were recapitulated with noise carriers (Fig. 7C,D): both FSL and FSL jitter increased with earplugging, and remediation decreased both measures to levels that did not differ from those of controls (FSL: KW ANOVA: $\chi_{(3,261)}^{2}=26.1, p<0.0001$; Mann-Whitney: EPSil vs CtSil: $p<0.0004$; EPSil vs EPGap: $p<0.015$; CtSil vs EPGap: $p=$ 0.9; FSL jitter: KW ANOVA: $\chi_{(3,261)}^{2}=$ 28.8, $p<0.0001$; Mann-Whitney: EPSil vs CtSil: $p<0.002$; EPSil vs EPGap: $p<$ 0.0002; CtSil vs EPGap: $p=0.1$ ). It was not possible to assess whether this relationship also existed for the subset of highly gap-sensitive cells, because the earplugged group did not have enough sensitive cells to contribute to the analysis, as can be seen in the distribution of GDTs in Figure $7 B$.

\section{Effects of brief stimulus exposure on control animals}

Behaviorally, stimulus exposure did not significantly improve GDTs for control animals, but did significantly reduce GDT variability in controls, due to more animals achieving low thresholds. This was the case both across sessions and for best performance (Fig. 2, gray symbols; Levene's test for unequal variances, CtSil vs CtGap: across sessions $F_{(1,121)}=12.6, p=0.0006$; best session $\left.F_{(1,39)}=8.3, p=0.006\right)$. This reduction in variance with stimulus exposure also occurred in the earplugged animals (Fig. 2, orange symbols).

In control animals, neural GDTs did not significantly differ after stimulus exposure, despite median values shifting slightly lower (Fig. 4, gray symbols; Mann-Whitney, CtSil vs CtGap: $p=$ 0.47 ). Some basic encoding elements were affected by stimulus exposure, including sound threshold levels and spontaneous firing rates (Fig. 6C,E; Mann-Whitney, threshold decibels: CtSil vs CtGap $p<0.03$; spontaneous firing rates: CtSil vs CtGap $p<$ $0.005)$. However, there was a strong effect of stimulus exposure on general temporal processing in control animals. Similar to FSL and FSL jitter in earplugged animals, FSL and FSL jitter in controls were affected by stimulus exposure. Notably, stimulus exposure reduced both FSL and FSL jitter to yield even more precise 
firing than that of controls (Fig. 5A, B, gray symbols; MannWhitney, CtSil vs CtGap: FSL $p<0.03$, FSL jitter $p<0.007)$. The same effects were present in highly gap-sensitive neurons, i.e., the subset with GDTs $\leq 10 \mathrm{~ms}$. Stimulus exposure reduced both FSL and FSL jitter to yield firing precisions better than those of controls (Fig. 5C,D, gray symbols; Mann-Whitney, CtSil vs CtGap: FSL $p<0.03$, FSL jitter $p<0.006$ ).

\section{Discussion}

We have demonstrated that transiently depriving animals of auditory experience during a critical window of development impaired the perception of short gaps. This loss of sensitivity was reflected by higher GDTs across ACx neurons, and fewer neurons with sensitive GDTs. Early transient hearing loss thus induced CNS dysfunction, which manifested in perceptual problems outlasting the period of deprivation. The deprivation had broad effects on ACx response properties, including firing precision, FSL, response magnitude, dynamic range, and response threshold. To rescue these deficits, control and deprived animals were passively exposed to three brief sessions of gaps in noise within a small enclosure, and compared with animals exposed to silence. Gap exposure fully restored behavioral GDTs to control levels in deprived animals. Concurrently, all cortical response properties shifted by deprivation were restored to control levels.

The auditory deprivation was constrained to a time window when transient deprivation disrupts intrinsic and synaptic properties in the ACx (Mowery et al., 2015), suggesting behavioral consequences for percepts (i.e., gap detection) that rely on the cortex. We have shown that deprivation during this window impairs neural and behavioral GDTs and has widespread effects on cortical response properties. These neural shifts could underlie a wider range of perceptual deficits known to arise from early hearing loss, including the detection of amplitude and frequency modulation (Halliday and Bishop, 2006; Rosen et al., 2012; Buran et al., 2014; von Trapp et al., 2017). As our manipulation was confined to a short developmental window, the deficits seen here may contribute to speech and language delays experienced by children with transient hearing loss arising from recurrent otitis media.

Early remediation of these deficits is critical, because early deficits predict later problems that can be long-lasting. In children with congenital hearing loss, language outcomes and cortical latencies correlate with the age of cochlear implantation (Sharma et al., 2007; Levine et al., 2016). Language delays can be predicted from early temporal processing ability, including gap detection (Trehub and Henderson, 1996; Benasich and Tallal, 2002; Benasich et al., 2006; Muluk et al., 2011), indicating a need for early intervention. Extensive training regimens are effective for children with language problems (Gaab et al., 2007), but are time-consuming and require extensive engagement. The effectiveness of our brief stimulus exposure suggests the possibility of rescue by an efficient remediation regime. Perceptual training with basic auditory cues can improve language perception (Lakshminarayanan and Tallal, 2007). This, along with our rescue of cortical responses, indicates that brief stimulus exposure has the potential to improve not only gap detection, but also more general deficits in auditory processing.

\section{Impaired gap perception and neural coding: mechanisms of transient binaural deprivation}

Transient early deprivation is rarely studied, despite its greater clinical relevance to otitis media than extended manipulations. Early transient unilateral deprivation revealed cortical deficits in binaural integration (Polley et al., 2013), and transient early bin- aural deprivation-induced behavioral deficits in modulation detection (Caras and Sanes, 2015). Our findings are consistent with those of these studies. Other manipulations that induce early deprivation, from congenital deafness to rearing in constant noise, have similar effects on sound-evoked responses in both the cortex and the inferior colliculus (IC) to those observed here: reduced firing rates, increased latencies, and reduced dynamic range (Klinke et al., 1999; Shepherd et al., 1999; Takahashi et al., 2006; Sharma et al., 2007; Gao et al., 2009; Vollmer and Beitel, 2011). Changes to cortical and/or collicular circuitry and intrinsic neural properties could reduce firing rates. Early deprivation reduced current injection-evoked cortical firing rates (Mowery et al., 2015), and altered neurotransmitter release of inhibitory and excitatory afferents in the IC and $\mathrm{ACx}$, causing a smaller response to the second of two stimuli on a timescale similar to our stimuli (Vale and Sanes, 2002; Xu et al., 2007; Takesian et al., 2010). These effects likely reduced the gap-offset response (i.e., response to the second stimulus; Fig. $4 E$ ). Although deprivation reduces inhibitory strength in both the ACx and IC (Vale et al., 2003; Takesian et al., 2012), this seems insufficient to overcome the effects of increased short-term depression and reduced intrinsic excitability on the gap-offset response.

In thalamocortical slice preparations, thalamic-evoked EPSP latencies and jitter are both increased (Xu et al., 2007), which may explain the increased FSLs and jitter shown here. Longer latencies and reduced firing precision should disrupt a wide range of percepts that rely on precise timing. The gap-offset response relies on timing of inhibitory and excitatory inputs onto cortical cells (Weible et al., 2014), so delayed or imprecise inputs could affect temporal summation and reduce the postsynaptic response. This temporal imprecision may arise before the ACx. For example, there is impaired gap coding in the IC of aged mice that matches the raised GDTs seen during aging (Walton et al., 1998; Allen et al., 2003). However, at a functional level, animals raised with earplugs akin to this study (P11-P23) had normal ABRs when tested at the time point of our neural recordings. Both ABR amplitudes and latencies of waves measuring activity from the auditory nerve through IC inputs (Boettcher, 2002) were identical to those of controls (Caras and Sanes, 2015). Based on these measures, early deprivation did not functionally alter auditory brainstem regions, though higher resolution recordings are needed to confirm this.

The altered cortical responses may not exclusively impair perception, but they should contribute because cortical activity immediately following gaps is causally related to gap detection. Optogenetic activation of pyramidal cells at gap offset improved behavioral GDTs, while activation of inhibitory cells worsened detection (Weible et al., 2014). We quantified cortical GDT based on the response magnitude following gap offset knowing that this drives behavioral detection. Gap-offset responses were smaller after deprivation, which resulted in fewer cells with short GDTs (Fig. $4 B, E)$. From the perspective of population coding, a smaller proportion of neurons with short GDTs should degrade gap detection. The ideal observer model supports this idea, showing worse detection for the cell population with fewer short GDTs. As an extension, the poorer gap-detection abilities seen in juvenile or aged individuals may be attributable to fewer neurons with low GDTs, as demonstrated in those groups (Barsz et al., 2002; Zhao et al., 2015).

\section{Mechanisms of remediation: brief stimulus exposure rescues gap detection}

Stimulus exposure occurred after the developmental time window where transient deprivation induced cortical changes or perceptual deficits (Caras and Sanes, 2015; Mowery et al., 2015). 
Despite this, three $1 \mathrm{~h}$ sessions of exposure to gaps were sufficient to fully remediate the behavioral and neural deficits arising from early deprivation. This is unexpected because beyond critical periods, active attention is usually necessary for remediation, and even extended periods of passive exposure typically have little effect (Keuroghlian and Knudsen, 2007; Zhou and Merzenich, 2009; Benasich et al., 2014). Auditory deprivation may have extended the critical period. This may explain one counterexample, where constant tone-burst exposure for a month following early deprivation improved ACx gap detection, though not to control levels (Jiang et al., 2015). While our earplugging may have extended the critical period, we found that stimulus exposure changed response properties and improved GDTs even in control animals (Green et al., 2016). The reduced efficacy of exposure in controls may be attributable to ceiling effects in performance or neural response elements. Nevertheless, the timing of remediation immediately following transient deprivation may have contributed to its efficacy, and it remains to be studied whether remediation in adulthood is effective.

The improvement induced by stimulus exposure indicates that implicit learning has occurred. Nonexplicit stimulus elements, such as statistical structure in language, are naturally learned during development. For example, 9-month-olds but not 6 -month-olds prefer words with their native language stress pattern (Jusczyk et al., 1993). Even in adults, statistical structure of language or tone sequences can be learned during unattended exposure in an experimental setting (Saffran et al., 1999). Rather than exposure being purely passive, task performance may create a sensitized state in which sensory stimulation induces learning (Seitz and Dinse, 2007; Wright and Zhang, 2009). For example, unattended stimuli were learned when presented in conjunction with or alternating with attended stimuli, but not when passively presented (Seitz and Watanabe, 2003; Wright et al., 2015). Furthermore, learning unattended stimuli during task performance correlated with rapid EEG plasticity in the ACx (Andrillon et al., 2015). This suggests involvement of the mechanisms underlying associative learning, where stimulating cholinergic nucleus basalis (NB) afferents to the cortex modifies $\mathrm{ACx}$ response properties (Metherate and Ashe, 1993; Edeline et al., 1994; Kilgard and Merzenich, 1998) and improves sensory perception (Bieszczad et al., 2013; Froemke et al., 2013). Our stimulus exposure, via isolation in a small enclosure, may have induced heightened arousal or stress, which would activate amygdalar inputs to NB (Russchen et al., 1985; McGaugh et al., 2002), allowing acetylcholine in the ACx to remodel cortical activity (Letzkus et al., 2011; Pi et al., 2013), leading to improved performance. Separately, it has been shown that early in the critical period, a brief ( $\sim 5 \mathrm{~min})$ noise pulse exposure reduced inhibitory duration and improved $\mathrm{ACx}$ temporal resolution (Cai et al., 2017). Such early inhibitory plasticity could explain our results if earplugging sufficiently extended the critical period, although the effect in our controls and in those of Green et al., 2016, suggests that additional mechanisms may be involved.

The nature of the exposure stimuli may contribute to implicit learning and cortical remodeling. The statistical structure of stimuli can shape perception and tune cortical responses (Bao, 2015). For example, extended exposure to sound sequences created combination-sensitive neurons responsive to these sequences (Nakahara et al., 2004). This implies that more complex sound exposure may improve degraded perception by allowing a wider range of tuning properties. Exposing the deprived animals to gaps ranging from 2 to $30 \mathrm{~ms}$ increased the number of gap-sensitive cells. The shifts in cortical representation and perceptual acuity match the statistics of the exposure stimuli, and are consistent with statistical learning. However, $\mathrm{ACx}$ response properties beyond GDTs also improve, which may improve detection of other stimuli. Alternatively, any stimulus exposure may have been sufficient to remediate gap detection and $\mathrm{ACx}$ responses in deprived animals. For example, exposure of noise-reared animals to an enriched acoustic environment rescued deprivation-induced deficits (Zhu et al., 2014). Although the mechanisms and parameters of stimulus exposure need further study, the remediation seen here indicates the potential of this approach as an efficient therapeutic tool to remediate auditoryprocessing deficits.

\section{References}

Allen PD, Burkard RF, Ison JR, Walton JP (2003) Impaired gap encoding in aged mouse inferior colliculus at moderate but not high stimulus levels. Hear Res 186:17-29. CrossRef Medline

Amitay S, Irwin A, Moore DR (2006) Discrimination learning induced by training with identical stimuli. Nat Neurosci 9:1446-1448. CrossRef Medline

Andrillon T, Kouider S, Agus T, Pressnitzer D (2015) Perceptual learning of acoustic noise generates memory-evoked potentials. Curr Biol 25:28232829. CrossRef Medline

Bao S (2015) Perceptual learning in the developing auditory cortex. Eur J Neurosci 41:718-724. CrossRef Medline

Barsz K, Ison JR, Snell KB, Walton JP (2002) Behavioral and neural measures of auditory temporal acuity in aging humans and mice. Neurobiol Aging 23:565-578. CrossRef Medline

Benasich AA, Tallal P (2002) Infant discrimination of rapid auditory cues predicts later language impairment. Behav Brain Res 136:31-49. CrossRef Medline

Benasich AA, Choudhury N, Friedman JT, Realpe-Bonilla T, Chojnowska C, Gou Z (2006) The infant as a prelinguistic model for language learning impairments: predicting from event-related potentials to behavior. Neuropsychologia 44:396-411. CrossRef Medline

Benasich AA, Choudhury NA, Realpe-Bonilla T, Roesler CP (2014) Plasticity in developing brain: active auditory exposure impacts prelinguistic acoustic mapping. J Neurosci 34:13349-13363. CrossRef Medline

Bieszczad KM, Miasnikov AA, Weinberger NM (2013) Remodeling sensory cortical maps implants specific behavioral memory. Neuroscience 246: 40-51. CrossRef Medline

Boettcher FA (2002) Presbyacusis and the auditory brainstem response. J Speech Lang Hear Res 45:1249-1261. CrossRef Medline

Buran BN, Sarro EC, Manno FA, Kang R, Caras ML, Sanes DH (2014) A sensitive period for the impact of hearing loss on auditory perception. J Neurosci 34:2276-2284. CrossRef Medline

Cai D, Han R, Liu M, Xie F, You L, Zheng Y, Zhao L, Yao J, Wang Y, Yue Y, Schreiner CE, Yuan K (2017) A critical role of inhibition in temporal processing maturation in the primary auditory cortex. Cereb Cortex 1-15. CrossRef Medline

Caras ML, Sanes DH (2015) Sustained perceptual deficits from transient sensory deprivation. J Neurosci 35:10831-10842. CrossRef Medline

Catts HW, Fey ME, Zhang X, Tomblin JB (1999) Language basis of reading and reading disabilities: evidence from a longitudinal investigation. Sci Studies Reading 3:331-361. CrossRef

Chang EF, Merzenich MM (2003) Environmental noise retards auditory cortical development. Science 300:498-502. CrossRef Medline

Diedler J, Pietz J, Bast T, Rupp A (2007) Auditory temporal resolution in children assessed by magnetoencephalography. Neuroreport 18:16911695. CrossRef Medline

Edeline JM, Hars B, Maho C, Hennevin E (1994) Transient and prolonged facilitation of tone-evoked responses induced by basal forebrain stimulations in the rat auditory cortex. Exp Brain Res 97:373-386. Medline

Eggermont JJ (2000) Neural responses in primary auditory cortex mimic psychophysical, across-frequency-channel, gap-detection thresholds. J Neurophysiol 84:1453-1463. Medline

Eggermont JJ (2015) Animal models of auditory temporal processing. Int J Psychophysiol 95:202-215. CrossRef Medline

Fechter LD, Sheppard L, Young JS, Zeger S (1988) Sensory threshold estimation from a continuously graded response produced by reflex modification audiometry. J Acoust Soc Am 84:179-185. CrossRef Medline

Froemke RC, Carcea I, Barker AJ, Yuan K, Seybold BA, Martins AR, Zaika N, 
Bernstein H, Wachs M, Levis PA, Polley DB, Merzenich MM, Schreiner CE (2013) Long-term modification of cortical synapses improves sensory perception. Nat Neurosci 16:79-88. CrossRef Medline

Gaab N, Gabrieli JD, Deutsch GK, Tallal P, Temple E (2007) Neural correlates of rapid auditory processing are disrupted in children with developmental dyslexia and ameliorated with training: an fMRI study. Restor Neurol Neurosci 25:295-310. Medline

Gao F, Zhang J, Sun X, Chen L (2009) The effect of postnatal exposure to noise on sound level processing by auditory cortex neurons of rats in adulthood. Physiol Behav 97:369-373. CrossRef Medline

Gay JD, Voytenko SV, Galazyuk AV, Rosen MJ (2014) Developmental hearing loss impairs signal detection in noise: putative central mechanisms. Front Syst Neurosci 8:162. CrossRef Medline

Geisler WS (2011) Contributions of ideal observer theory to vision research. Vision Res 51:771-781. CrossRef Medline

Gravel JS, Wallace IF, Ruben RJ (1996) Auditory consequences of early mild hearing loss associated with otitis media. Acta Otolaryngol 116:219-221. CrossRef Medline

Green DB, Ohlemacher J, Rosen MJ (2016) Benefits of stimulus exposure: developmental learning independent of task performance. Front Neurosci 10:263. CrossRef Medline

Hall JW, Grose JH (1994) Effect of otitis media with effusion on comodulation masking release in children. J Speech Hear Res 37:1441-1449. CrossRef Medline

Halliday LF, Bishop DV (2006) Is poor frequency modulation detection linked to literacy problems? A comparison of specific reading disability and mild to moderate sensorineural hearing loss. Brain Lang 97:200-213. CrossRef Medline

Hamann I, Gleich O, Klump GM, Kittel MC, Strutz J (2004) Age-dependent changes of gap detection in the Mongolian gerbil (Meriones unguiculatus). J Assoc Res Otolaryngol 5:49-57. CrossRef Medline

Han YK, Köver H, Insanally MN, Semerdjian JH, Bao S (2007) Early experience impairs perceptual discrimination. Nat Neurosci 10:1191-1197. CrossRef Medline

Harris KC, Wilson S, Eckert MA, Dubno JR (2012) Human evoked cortical activity to silent gaps in noise: effects of age, attention, and cortical processing speed. Ear Hear 33:330-339. CrossRef Medline

Ihlefeld A, Chen YW, Sanes DH (2016) Developmental conductive hearing loss reduces modulation masking release. Trends Hear 20:2331216516676255. CrossRef Medline

Ison JR, Hammond GR, Krauter EE (1973) Effects of experience on stimulus-produced reflex inhibition in the rat. J Comp Physiol Psychol 83:324-336. CrossRef Medline

Ison JR, O'Connor K, Bowen GP, Bocirnea A (1991) Temporal resolution of gaps in noise by the rat is lost with functional decortication. Behav Neurosci 105:33-40. CrossRef Medline

Jiang C, Xu X, Yu L, Xu J, Zhang J (2015) Environmental enrichment rescues the degraded auditory temporal resolution of cortical neurons induced by early noise exposure. Eur J Neurosci 42:2144-2154. CrossRef Medline

Jusczyk PW, Cutler A, Redanz NJ (1993) Infants' preference for the predominant stress patterns of English words. Child Dev 64:675-687. CrossRef Medline

Kelly JB, Rooney BJ, Phillips DP (1996) Effects of bilateral auditory cortical lesions on gap-detection thresholds in the ferret (Mustela putorius). Behav Neurosci 110:542-550. CrossRef Medline

Keuroghlian AS, Knudsen EI (2007) Adaptive auditory plasticity in developing and adult animals. Prog Neurobiol 82:109-121. CrossRef Medline

Kilgard MP, Merzenich MM (1998) Cortical map reorganization enabled by nucleus basalis activity. Science 279:1714-1718. CrossRef Medline

Klinke R, Kral A, Heid S, Tillein J, Hartmann R (1999) Recruitment of the auditory cortex in congenitally deaf cats by long-term cochlear electrostimulation. Science 285:1729-1733. CrossRef Medline

Köver H, Gill K, Tseng YT, Bao S (2013) Perceptual and neuronal boundary learned from higher-order stimulus probabilities. J Neurosci 33:36993705. CrossRef Medline

Kral A, Eggermont JJ (2007) What's to lose and what's to learn: development under auditory deprivation, cochlear implants and limits of cortical plasticity. Brain Res Rev 56:259-269. CrossRef Medline

Lakshminarayanan K, Tallal P (2007) Generalization of non-linguistic auditory perceptual training to syllable discrimination. Restor Neurol Neurosci 25:263-272. Medline
Lanphear BP, Byrd RS, Auinger P, Hall CB (1997) Increasing prevalence of recurrent otitis media among children in the United States. Pediatrics 99:E1. CrossRef Medline

Letzkus JJ, Wolff SB, Meyer EM, Tovote P, Courtin J, Herry C, Lüthi A (2011) A disinhibitory microcircuit for associative fear learning in the auditory cortex. Nature 480:331-335. CrossRef Medline

Levine D, Strother-Garcia K, Golinkoff RM, Hirsh-Pasek K (2016) Language development in the first year of life: what deaf children might be missing before cochlear implantation. Otol Neurotol 37:e56-e62. CrossRef Medline

Longenecker RJ, Galazyuk AV (2012) Methodological optimization of tinnitus assessment using prepulse inhibition of the acoustic startle reflex. Brain Res 1485:54-62. CrossRef Medline

Longenecker RJ, Alghamdi F, Rosen MJ, Galazyuk AV (2016) Prepulse inhibition of the acoustic startle reflex vs. auditory brainstem response for hearing assessment. Hear Res 339:80-93. CrossRef Medline

McGaugh JL, McIntyre CK, Power AE (2002) Amygdala modulation of memory consolidation: interaction with other brain systems. Neurobiol Learn Mem 78:539-552. CrossRef Medline

Metherate R, Ashe JH (1993) Nucleus basalis stimulation facilitates thalamocortical synaptic transmission in the rat auditory cortex. Synapse 14:132143. CrossRef Medline

Mowery TM, Kotak VC, Sanes DH (2015) Transient hearing loss within a critical period causes persistent changes to cellular properties in adult auditory cortex. Cereb Cortex 25:2083-2094. CrossRef Medline

Muluk NB, Yalçinkaya F, Keith RW (2011) Random gap detection test and random gap detection test-expanded: results in children with previous language delay in early childhood. Auris Nasus Larynx 38:6-13. CrossRef Medline

Nakahara H, Zhang LI, Merzenich MM (2004) Specialization of primary auditory cortex processing by sound exposure in the "critical period." Proc Natl Acad Sci U S A 101:7170-7174. CrossRef Medline

Parisi T, Ison JR (1979) Development of the acoustic startle response in the rat: ontogenetic changes in the magnitude of inhibition by prepulse stimulation. Dev Psychobiol 12:219-230. CrossRef Medline

Pi HJ, Hangya B, Kvitsiani D, Sanders JI, Huang ZJ, Kepecs A (2013) Cortical interneurons that specialize in disinhibitory control. Nature 503: 521-524. CrossRef Medline

Polley DB, Thompson JH, Guo W (2013) Brief hearing loss disrupts binaural integration during two early critical periods of auditory cortex development. Nat Commun 4:2547. CrossRef Medline

Rosen MJ, Sarro EC, Kelly JB, Sanes DH (2012) Diminished behavioral and neural sensitivity to sound modulation is associated with moderate developmental hearing loss. PLoS One 7:e41514. CrossRef Medline

Russchen FT, Amaral DG, Price JL (1985) The afferent connections of the substantia innominata in the monkey, Macaca fascicularis. J Comp Neurol 242:1-27. CrossRef Medline

Saffran JR, Johnson EK, Aslin RN, Newport EL (1999) Statistical learning of tone sequences by human infants and adults. Cognition 70:27-52. CrossRef Medline

Sanes DH, Kotak VC (2011) Developmental plasticity of auditory cortical inhibitory synapses. Hear Res 279:140-148. CrossRef Medline

Sarro EC, Sanes DH (2011) The cost and benefit of juvenile training on adult perceptual skill. J Neurosci 31:5383-5391. CrossRef Medline

Seitz AR, Dinse HR (2007) A common framework for perceptual learning. Curr Opin Neurobiol 17:148-153. CrossRef Medline

Seitz AR, Watanabe T (2003) Psychophysics: is subliminal learning really passive? Nature 422:36. CrossRef Medline

Sharma A, Gilley PM, Dorman MF, Baldwin R (2007) Deprivation-induced cortical reorganization in children with cochlear implants. Int J Audiol 46:494-499. CrossRef Medline

Shepherd RK, Baxi JH, Hardie NA (1999) Response of inferior colliculus neurons to electrical stimulation of the auditory nerve in neonatally deafened cats. J Neurophysiol 82:1363-1380. Medline

Sun W, Tang L, Allman BL (2011) Environmental noise affects auditory temporal processing development and NMDA-2B receptor expression in auditory cortex. Behav Brain Res 218:15-20. CrossRef Medline

Syka J, Rybalko N, Mazelová J, Druga R (2002) Gap detection threshold in the rat before and after auditory cortex ablation. Hear Res 172:151-159. CrossRef Medline

Takahashi K, Hishida R, Kubota Y, Kudoh M, Takahashi S, Shibuki K (2006) Transcranial fluorescence imaging of auditory cortical plasticity regulated 
by acoustic environments in mice. Eur J Neurosci 23:1365-1376. CrossRef Medline

Takesian AE, Kotak VC, Sanes DH (2009) Developmental hearing loss disrupts synaptic inhibition: implications for auditory processing. Future Neurol 4:331-349. CrossRef Medline

Takesian AE, Kotak VC, Sanes DH (2010) Presynaptic GABA B $_{\text {receptors }}$ regulate experience-dependent development of inhibitory short-term plasticity. J Neurosci 30:2716-2727. CrossRef Medline

Takesian AE, Kotak VC, Sanes DH (2012) Age-dependent effect of hearing loss on cortical inhibitory synapse function. J Neurophysiol 107:937-947. CrossRef Medline

Thomas H, Tillein J, Heil P, Scheich H (1993) Functional organization of auditory cortex in the mongolian gerbil (Meriones unguiculatus). I. Electrophysiological mapping of frequency representation and distinction of fields. Eur J Neurosci 5:882-897. CrossRef Medline

Threlkeld SW, Penley SC, Rosen GD, Fitch RH (2008) Detection of silent gaps in white noise following cortical deactivation in rats. Neuroreport 19:893-898. CrossRef Medline

Trehub SE, Henderson JL (1996) Temporal resolution in infancy and subsequent language development. J Speech Hear Res 39:1315-1320. CrossRef Medline

Vale C, Sanes DH (2002) The effect of bilateral deafness on excitatory and inhibitory synaptic strength in the inferior colliculus. Eur J Neurosci 16: 2394-2404. CrossRef Medline

Vale C, Schoorlemmer J, Sanes DH (2003) Deafness disrupts chloride transporter function and inhibitory synaptic transmission. J Neurosci 23: 7516-7524. Medline

Vollmer M, Beitel RE (2011) Behavioral training restores temporal processing in auditory cortex of long-deaf cats. J Neurophysiol 106:2423-2436. CrossRef Medline

von Trapp G, Aloni I, Young S, Semple MN, Sanes DH (2017) Developmental hearing loss impedes auditory task learning and performance in gerbils. Hear Res 347:3-10. CrossRef Medline

Wagner E, Klump GM, Hamann I (2003) Gap detection in Mongolian gerbils (Meriones unguiculatus). Hear Res 176:11-16. CrossRef Medline

Walton JP, Frisina RD, O’Neill WE (1998) Age-related alteration in process- ing of temporal sound features in the auditory midbrain of the CBA mouse. J Neurosci 18:2764-2776. Medline

Weible AP, Moore AK, Liu C, DeBlander L, Wu H, Kentros C, Wehr M (2014) Perceptual gap detection is mediated by gap termination responses in auditory cortex. Curr Biol 24:1447-1455. CrossRef Medline

Whitton JP, Polley DB (2011) Evaluating the perceptual and pathophysiological consequences of auditory deprivation in early postnatal life: a comparison of basic and clinical studies. J Assoc Res Otolaryngol 12:535547. CrossRef Medline

Wright BA, Zhang Y (2009) A review of the generalization of auditory learning. Philos Trans R Soc Lond B Biol Sci 364:301-311. CrossRef Medline

Wright BA, Sabin AT, Zhang Y, Marrone N, Fitzgerald MB (2010) Enhancing perceptual learning by combining practice with periods of additional sensory stimulation. J Neurosci 30:12868-12877. CrossRef Medline

Wright BA, Baese-Berk MM, Marrone N, Bradlow AR (2015) Enhancing speech learning by combining task practice with periods of stimulus exposure without practice. J Acoust Soc Am 138:928-937. CrossRef Medline

Xu H, Kotak VC, Sanes DH (2007) Conductive hearing loss disrupts synaptic and spike adaptation in developing auditory cortex. J Neurosci 27: 9417-9426. CrossRef Medline

Zhang J, Chen L, Gao F, Pu Q, Sun X (2008) Noise exposure at young age impairs the auditory object exploration behavior of rats in adulthood. Physiol Behav 95:229-234. CrossRef Medline

Zhang LI, Bao S, Merzenich MM (2002) Disruption of primary auditory cortex by synchronous auditory inputs during a critical period. Proc Natl Acad Sci U S A 99:2309-2314. CrossRef Medline

Zhao Y, Xu X, He J, Xu J, Zhang J (2015) Age-related changes in neural gap detection thresholds in the rat auditory cortex. Eur J Neurosci 41:285292. CrossRef Medline

Zhou X, Merzenich MM (2009) Developmentally degraded cortical temporal processing restored by training. Nat Neurosci 12:26-28. CrossRef Medline

Zhu X, Wang F, Hu H, Sun X, Kilgard MP, Merzenich MM, Zhou X (2014) Environmental acoustic enrichment promotes recovery from developmentally degraded auditory cortical processing. J Neurosci 34:54065415. CrossRef Medline 